\title{
Modeling of electrohydraulic forming of sheet metal parts
}

\author{
By Alexander V. Mamutov', Sergey F. Golovashchenko', Viacheslav S. Mamutov², and \\ John. J.F. Bonnen ${ }^{3}$ \\ ${ }^{1}$ Mechanical Engineering Department, School of Engineering and Computer Science, Oakland University, 2200 N Squirrel Rd, Rochester, MI \\ 48309, USA \\ ${ }^{2}$ Machines and Technologies of Metal Forming Department, Institute of Metallurgy, Mechanical Engineering and Transport, St Petersburg State \\ Polytechnic University, 29, Polytechnicheskaya st., St.Petersburg, 195251, Russia \\ ${ }^{3}$ Manufacturing Research Department, Ford Research and Advanced Engineering, 2101 Village Road, Dearborn, MI 48124, USA
}

\begin{abstract}
Electrohydraulic forming (EHF) is based upon the electro-hydraulic effect: a complex phenomenon related to the high voltage discharge inside the water filled chamber. The resulting shockwave in the liquid is propagated towards the blank, and the mass and momentum of the water in the shock wave accelerates the sheet metal blank toward the die. Methodology of numerical simulation of EHF processes was developed based upon LS-DYNA commercial code using Arbitrary Lagrange-Eulerian (ALE) Multi-Material formulation. The model incorporates
\end{abstract}


energy deposition inside the plasma channel, expansion of the channel driven by high pressure inside of it, propagation of the pressure pulse through the water filled chamber in contact with the rigid walls of the chamber and with the sheet metal blank being deformed. Comparison of the numerical and experimental results was performed on maximum pressure measured on the wall of the cylindrical chamber employing the membrane method.

The model was used to simulate multistage EHF of a complex geometry automotive part. Analysis of the results showed the complex nature of multistage EHF process: a clearly recognizable wave picture during the initial stage of the channel expansion which transitions to almost incompressible water flow during later stages.

Keywords:

Electrohydraulic forming

Plasma channel

Plastic deformation 


\section{Introduction}

According to Cheah and Heywood (2011), one of the most effective methods for reducing fuel consumption is through weight reduction of the vehicle body by replacement of mild steels with Advanced High Strength Steels (AHSS). Among the factors limiting the implementation of AHSS is their substantially lower formability compared to mild steels. Pulsed forming technologies such as Electromagnetic Forming (EMF), Explosive Forming (EF), and Electrohydraulic Forming (EHF) have been known for a number of decades and can help improve formability. A very detailed review of these technologies was reported by Psyk et al. (2011) and Mynors and Zhang (2002) illustrating their advantages compared to quasistatic onesided forming processes described by Singh (2003): the short duration of the applied forming pressure did not necessitate the large press sizes required for quasistatic forming, which generates a force equivalent to the pressure distributed across the blank surface.

The issue of the lower ductility of the prospective automotive alloys potentially can be resolved by some combination of traditional press stamping operations and pulsed forming processes. Very significant improvement of formability in pulsed forming reported in a number of experimental studies for steels and aluminum alloys was reviewed by Psyk et al. (2011).

EHF occupies an intermediate position between EF and EMF. A detailed comparison of EHF to EMF and EF was discussed by Golovashchenko et al. (2013). The advantage of EHF described by Davies and Austin (1970) in early applications was realized mostly in the reduction of capital investment for low volume aerospace applications. One fundamental advantage of EHF processes recently discussed by Golovashchenko et al. (2011) should be emphasized: it is capable of filling rather complex sheet metal forming shapes in one operation by providing a 
series of consecutive discharges which can fully form the blank into the die cavity and calibrate springback without opening the chamber and removing water from the tool. This methodology lowers the energy required for each discharge and hence lowers velocity of impact between the blank and the die providing more favorable conditions for die and chamber life as well as reduced formed blank rebound. In order to take full benefit of the advantages of EHF, it is necessary to develop a reliable simulation methodology which would enable EHF process and tooling design for practical applications in automotive industry.

\section{Review of previous publications on numerical simulation of EHF and EF processes.}

Since both EF and EHF processes deliver pulsed pressure to the surface of sheet metal blank using water as a pressure transmitting media, simulation of both processes share some commonalities and, therefore, should be reviewed together. Early attempts to predict the distribution of pressure on the surface of a deformable membrane based upon analytical methods predicting propagation of shock waves was taken by Cole (1948). Later on Rinehart and Pearson (1963) applied this approach to the analysis of EF while Chachin (1978) applied it to EHF taking into account specifics of energy deposition within EHF.

Among the semiempirical approaches described by Mynors and Zhang (2002) are the geometrical, the energy, and the impulse methods. All three provide analytical formulas for pulsed pressure, often as a function of time only. Similar approaches using the pressure pulse in explosive forming as a spatially uniform function exponentially decaying over time was used by Wijayathunga and Webb (2006). 
Simulation of EHF forming of the conical shape was discussed by Melander et al. (2013) where applied pressure was calculated as a ratio of discharged energy and volume of the chamber without taking into account an external electric circuit.

Analysis of pressure propagation in a cylindrical chamber was described by Vohnout et al. (2010) based upon CTH code developed for defense applications. Experimentally pulsed pressure at the bottom of the cylindrical chamber was defined employing the membrane method earlier described by Cole (1948) and assuming that the pressure pulse was created by the chemical explosion rather than by the electric discharge of capacitors. The analysis performed by the authors indicated that the pressure distribution was sensitive to the position of the initial discharge. This methodology is certainly the closest of what is available in the literature to the approach developed in this paper. However, limited access to the CTH code, as well as its specialized use for explosive processes only, makes its potential usage for EHF process design

problematic. Therefore, the authors of this paper have concentrated on developing the numerical technique based upon a commercially available code LS-DYNA which is broadly used throughout the world.

\section{Electrohydraulic Forming}

Early laboratory experiments and initial low volume industrial EHF applications for sheet metal forming are described by Bruno (1968). According to Chachin (1978), a high pressure, high temperature plasma channel is created between the tips of the electrodes during high voltage discharge of capacitors. The shockwave in the liquid, initiated by the expansion of the plasma 
channel, then propagates towards the blank at high speed, and the mass and momentum of the water in the shock wave forms the sheet metal blank into the die.

A typical configuration of EHF includes a discharge chamber, electrodes, forming die, and a pulse generator which consists of a high-voltage low-inductive bank of capacitors $\mathrm{C}$, a highvoltage/high-current discharge switch $\mathrm{D}$, and a charging/amplifying/rectifying circuit T-R-A is illustrated in Figure 1. The capacitor bank is capable of producing discharges of 5 to $25 \mathrm{kV}$ and can store energies up to $100 \mathrm{~kJ}$.

A sheet metal blank is placed on top of the discharge chamber. A one-sided die is positioned above the blank. After the air is evacuated from both sides of the blank, the chamber is filled with water, fully immersing the electrodes. After the voltage is applied to the electrodes, an electrical breakdown occurs between the exposed tips of the electrodes which leads to the formation of a stable plasma channel. The channel expands quickly resulting in shock waves of pressure which then continuously transform into flow of liquid. The pressure pulse propagates through the water and applies pressure to the surface of the blank forming it into the die cavity.

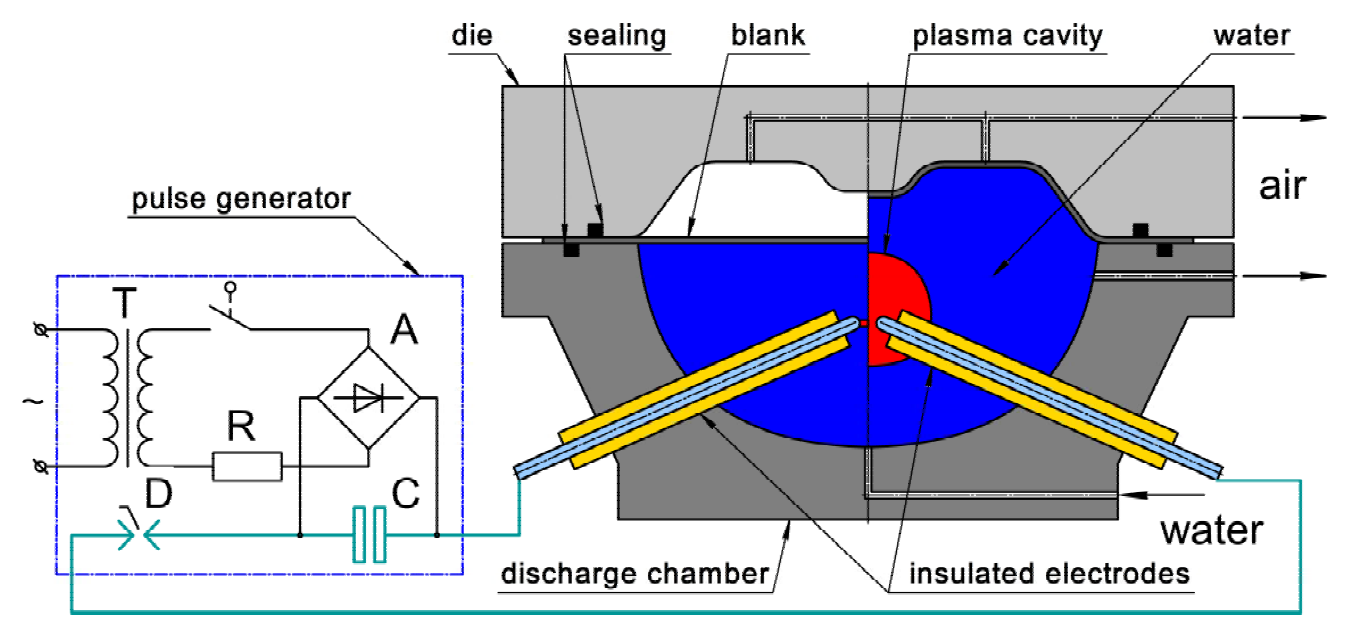

Figure 1. Schematic of sheet metal forming with an EHF chamber and die. 


\section{Suggested approach to numerical simulation of EHF}

In order to develop a numerical model of the EHF process, the following models need to be developed and later on coupled: 1) pressure generation in the discharge channel; 2) vaportemperature-pressure gradient around the discharge channel; 3) compressible liquid as a pressure transmitting media; 4) deformation of the blank in contact with the liquid and with the die.

\section{The energy deposited in the discharge channel}

The schematic of the electric circuit shown in Figure 2 was assumed to be the system equivalent to the real discharge circuit which includes the pulse generator, the electrical connections between the pulse generator and the EHF chamber, and the EHF chamber itself.

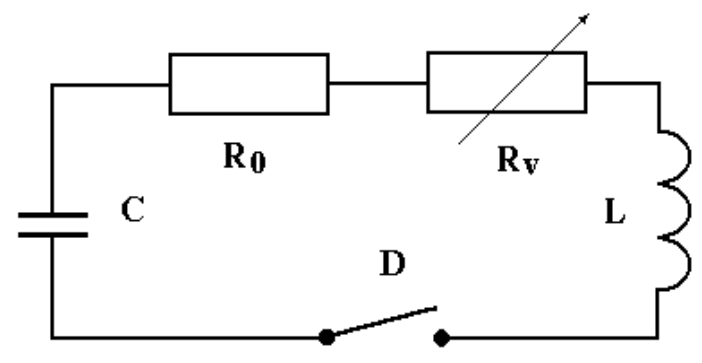

Figure 2. Schematic of electrical circuit at high-voltage discharge in a liquid: $\mathrm{C}$ - capacitance of the battery; $\mathrm{L}-$ total inductance of the system; $R_{0}$ - resistance of the circuit external to the discharge channel; $R_{v}-$ resistance of the discharge channel.

There are few approaches to determine the energy dissipated in the channel. One is a simulation of the discharge electrical circuit. The differential equation for current $i(t)$ in a circuit in Figure 2 includes a variable resistance term for the discharge channel $R_{v}$, the total resistance of 
the pulse generator and connecting cables $R_{0}$, and the overall inductance of the discharge circuit $L$. It can be written in the following form:

$$
\frac{d^{2} i}{d t^{2}}+\frac{R_{v}(i, t)+R_{0}}{L} \cdot \frac{d i}{d t}+\frac{1}{L C} i=0
$$

with the following initial conditions

$$
i(0)=0,\left.\quad \frac{d i}{d t}\right|_{t=0}=-\frac{U_{0}}{L},
$$

where $U_{0}$ - initial voltage of capacitor battery.

The electric power being pumped into the discharge channel can be defined by the following equation:

$$
N=i^{2} R_{v}(i, t)
$$

Integrating this equation against time gives the energy deposited in the discharge channel $E_{c h}(t)$ through the discharge process:

$$
E_{c h}=\int_{0}^{t} i^{2}(t) R_{v}(i, t) d t .
$$

To use this particular approach, the resistance of the channel as a function of time must be known, and deriving this function represents a separate and difficult simulation problem.

Another approach is to obtain the energy for the specific configuration from experimentally measured electrical current and voltage. The electric power can be calculated as:

$$
N=i(t) \cdot U(t)
$$

where $i(t)$ and $U(t)$ - are the current and voltage as measured by an oscilloscope across the electrodes, respectively. The electric current is measured by a Rogowski gauge while voltage is measured across the ends of the electrodes outside the EHF chamber. Corrections are then made by measuring the discharge process characteristics with low resistance connection of electrodes 
inside the chamber. Usually, the rise time of the discharge current is defined by the capacitance

and inductance of the system. In a number of applications of EHF technology where two straight electrodes are employed to produce the discharge, inductance of the overall system might be defined by the connection between the pulse generator and the EHF chamber. However, the active resistance of the plasma channel inside the EHF chamber is another factor which might affect the peak current of the discharge.

\section{The model of the plasma channel}

The plasma channel is modeled in LS-DYNA as an adiabatically expanding bubble of ideal gas. The electric energy is assumed to be introduced uniformly through the channel volume which initially is about $0.0001-0.05 \%$ of the chamber volume. Pressure in each finite element of the plasma channel can be calculated using the following equation of state (EOS) which describes the energy balance of adiabatically expanding ideal gas

$$
p_{c h}=(\gamma-1)\left(\rho / \rho_{0}\right) E,
$$

where

$\mathrm{p}_{\mathrm{ch}}-$ pressure at a given point of the discharge channel;

$\rho$ - current mass density of gas inside the channel;

$\rho_{0}$ - initial mass density of gas inside the channel;

$E$ - portion of the energy produced inside the channel;

$\gamma=1.26-$ adiabatic index for plasma produced from tap water inside the channel which corresponds to the range of plasma temperatures for the typical EHF process as shown in Naugolnych and Roy (1971). 
To define the material model with the equation of state (6) in the LS-DYNA input deck, the card *MAT_NULL is used together with the card *EOS_LINEAR_POLYNOMIAL_WITH_ENERGY_LEAK which defines pressure in the form

$$
\mathrm{p}_{\mathrm{ch}}=\mathrm{C}_{0}+\mathrm{C}_{1} \mu^{2}+\mathrm{C}_{2} \mu^{3}+\mathrm{C}_{3} \mu+\left(\mathrm{C}_{4}+\mathrm{C}_{5} \mu+\mathrm{C}_{6} \mu^{2}\right) \mathrm{E}^{\prime},
$$

where $\mathrm{C}_{0}, \mathrm{C}_{1}, \mathrm{C}_{2}, \mathrm{C}_{3}, \mathrm{C}_{4}, \mathrm{C}_{5}$, and $\mathrm{C}_{6}$ are user defined constants defined to reduce the equation to the form of $(6) ; \mu=1 / \mathrm{V}^{\prime}-1 ; \mathrm{V}^{\prime}=\rho_{0} / \rho$ is the relative volume; $\mathrm{E}^{\prime}$ is the internal energy per initial volume which increases according to a user defined energy deposition rate versus time curve. The initial plasma density is defined to be that of water at $\rho_{0}=1000 \mathrm{~kg} / \mathrm{m}^{3}$.

\section{Model of liquid}

The model of the liquid was used from LS-DYNA as ideal compressible liquid with the specific cavitation threshold using *MAT_ELASTIC_FLUID (*MAT_ELASTIC with option FLUID) model. The list of necessary parameters includes the initial mass density, compression modulus and negative pressure threshold corresponding to the beginning of cavitation. Cavitation pressure threshold is taken as zero. Technically, it must be any small value close to zero but not precisely zero to activate LS-DYNA cavitation logic. The value $-1.0^{*} 10^{-20}$ was chosen. The following material properties are employed: density $\rho_{0}=1000 \mathrm{~kg} / \mathrm{m}^{3}$, bulk modulus $\mathrm{k}=2.35^{*} 10^{9}$ Pa.

\section{Meshing technique and choice of solver}

Expansion of the discharge channel interacting with a liquid and interaction of liquid with a deformable blank was simulated using the Arbitrary Lagrange Eulerian (ALE) solver with MultiMaterial capability available in LS-DYNA. This approach eliminates the issue of substantial 
mesh distortion: the physical materials, called multi-materials groups (MMG), are moving through the space defined by the geometrical mesh which does not move. Few MMGs are allowed inside of one geometrical element, and the boundaries of actual physical objects are determined by the solver based on quantity of a particular MMG in neighboring elements.

\section{Model of sheet metal blank}

An elastic-plastic shell model incorporating bending stiffness in contact with the rigid die was employed for modeling of a sheet metal blank formation into a designated shape.

The influence of strain rate on the hardening law was accounted for by scaling the flow stress using the following factor:

$$
k_{d}=1+\left(\frac{\dot{\varepsilon}}{C}\right)^{1 / p}
$$

where $k_{d}$ is the scaling coefficient, $\dot{\varepsilon}$ is the strain rate, and $C$ and $p$ are strain-rate parameters. This model has the advantage in LS-DYNA that it can be used together with two material models which are commonly used in metal-forming simulations:

*MAT_PIECEWISE_LINEAR_PLASTICITY and *MAT_POWER_LAW_PLASTICITY. The flow stress is defined by a user-defined curve and is multiplied by the $k_{d}$ value. Alternatively, the power law material model may be used to define flow stress by following expression:

$$
\sigma_{f}=K \varepsilon^{m}\left(1+\left(\frac{\dot{\varepsilon}}{C}\right)^{1 / p}\right)
$$

where $\varepsilon$ is the plastic strain, $\mathrm{K}$ is the strength coefficient, $\mathrm{m}$ is the hardening exponent, $\dot{\varepsilon}$ is the strain rate, and $C$ and $p$ are the strain-rate parameters. 


\section{Experimental Verification}

The problem of an axisymmetric discharge in a cylindrical chamber was chosen to estimate correctness of developed energy input approach, since no interaction of liquid with deformable blank is required, and the model of such a problem is geometrically simple.

\section{Experimental Setup and Results}

The schematic of the experimental setup is shown in Figure 3 where capacitance $\mathrm{C}=50 \mu \mathrm{F}$. The cylindrical discharge chamber has the following dimensions: $D=100 \mathrm{~mm}$ and $L=160 \mathrm{~mm}$. A membrane pressure sensor is installed in the wall. A nichrome wire with a diameter of $0.3 \mathrm{~mm}$ is used for discharge initiation. An oscilloscope measures two signals: the electrical current, obtained from Rogowski coil and the voltage obtained from voltage divider. 


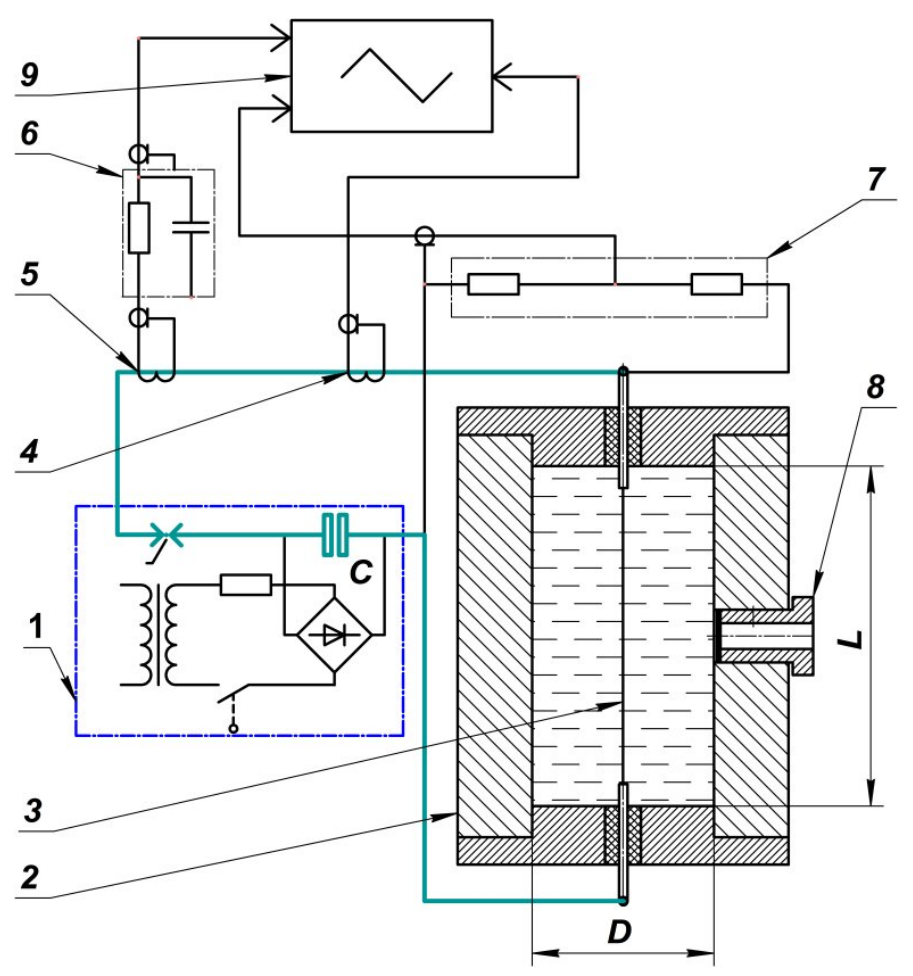

Figure 3. Schematic of experimental measurement of energy deposition and pulsed pressure in the discharge chamber: 1 - pulse generator, 2 - cylindrical discharge chamber filled with water, 3 - initiating wire, 4 - Rogowski coil which triggers oscilloscope, 5 - Rogowski coil for the current measurement, 6 - integrating $R C$-circuit, 7 voltage divider, 8 - membrane pressure sensor, 9 - impulse oscilloscope.

The relative error of measuring the current and the voltage was less than $5 \%$, and the membrane pressure sensor provides relative error about 15\% as shown by Vagin et al. (1990). The geometry of the discharge chamber, specifically length to radius ratio, is defined in such a way that boundary effects from the flat walls of the chamber do not affect the results from the pressure sensor. 
The discharge current $i(t)$ and voltage $u(t)$ obtained experimentally during discharge with $12.5 \mathrm{kV}$ initial voltage are shown in Figure 4.a. The energy deposition curve $N(t)$ calculated from these data according to formula (5) is shown in Figure 4.b.

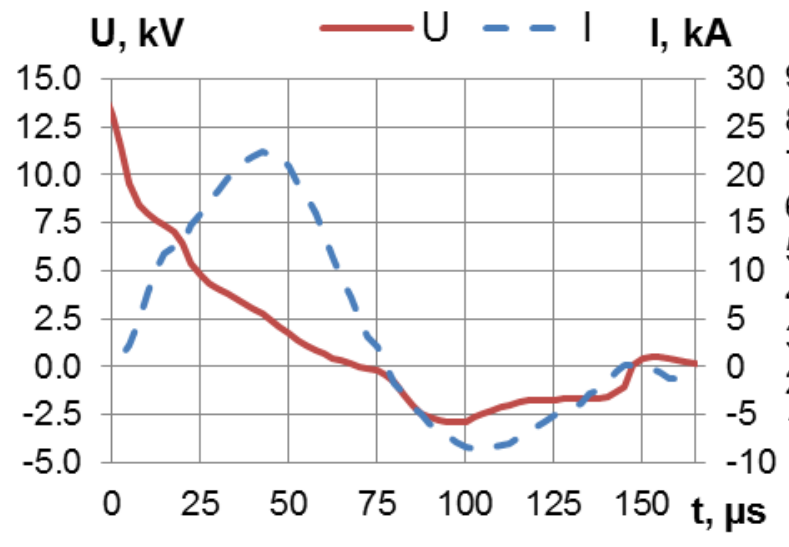

a)

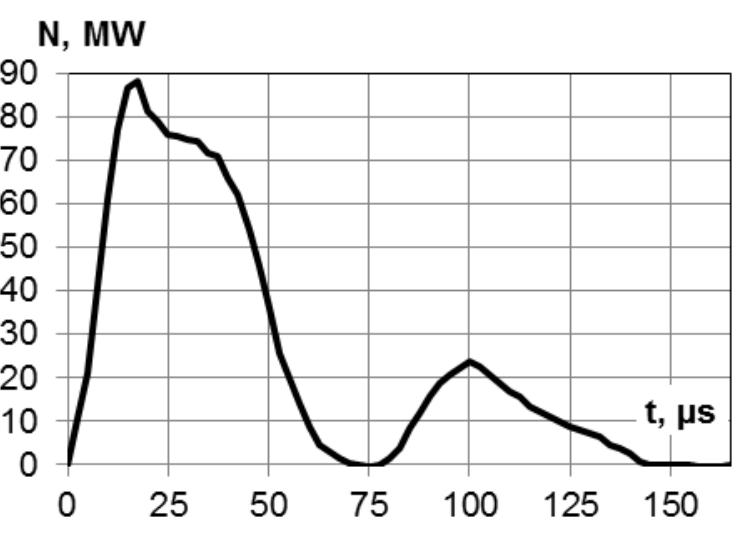

b)

Figure 4. Experimentally obtained current $i(t)$ and voltage $u(t)$ vs. time (a) and energy deposition law $N(t)$ (b).

The experimentally measured maximum pressure on the chamber wall was $79.5 \pm 6.5 \mathrm{MPa}$ with $95 \%$ confidence interval.

\section{Meshing Strategy for the Test Problem}

The simulation of the test was performed in plane strain formulation: a thin layer of the chamber was simulated using a single layer 3D element mesh restrained by the boundary conditions illustrated in Figure 5. The initial channel radius was $r_{k 0}=1 \mathrm{~mm}$, and the initial plasma density was $\rho_{p 0}=1000 \mathrm{~kg} / \mathrm{m}^{3}$. 


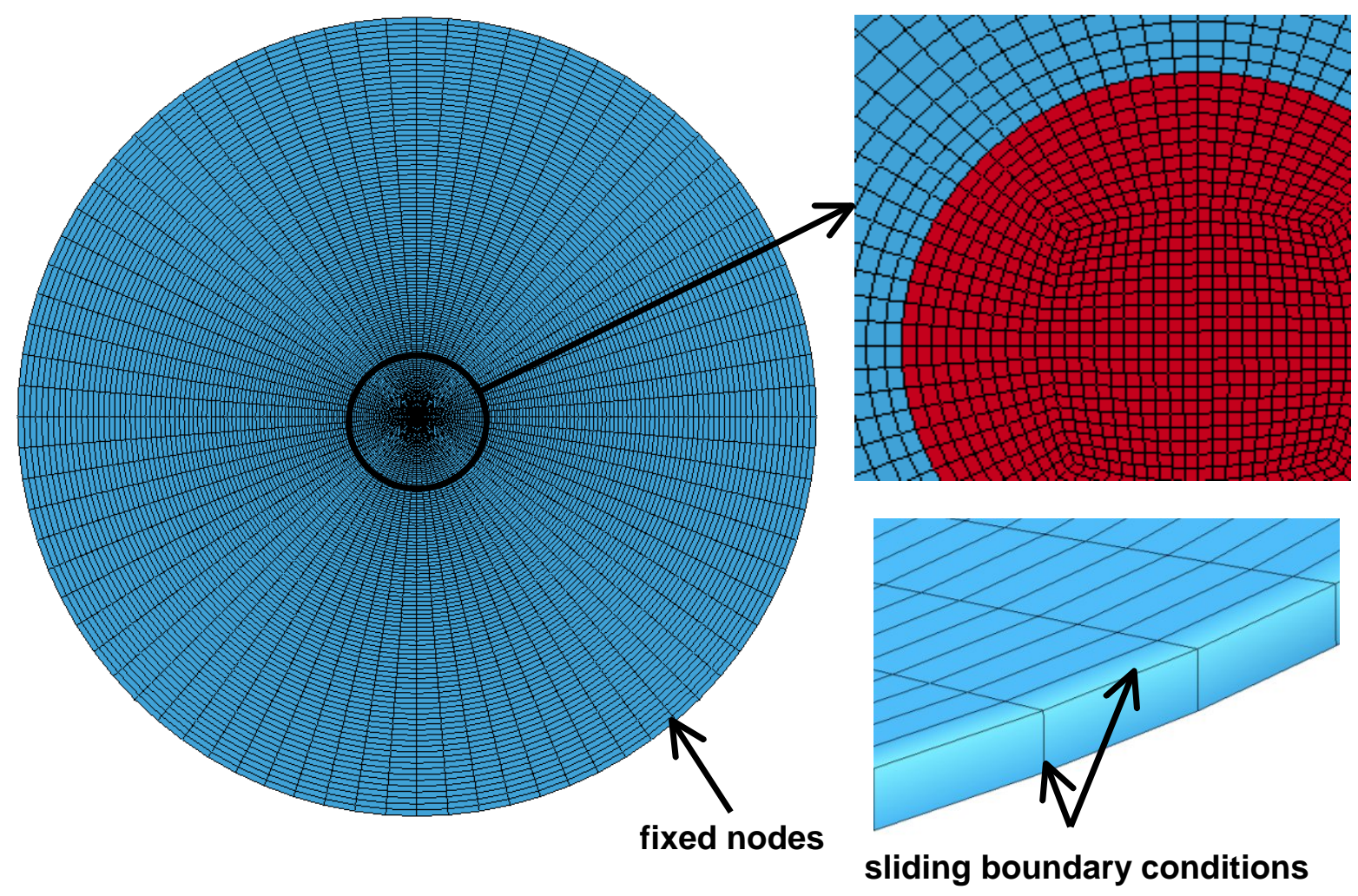

Figure 5. The plain-strain test case mesh.

\section{$\underline{\text { Results of Simulation and Comparison with Experiment }}$}

Figure 6 shows the shape of the discharge channel over time, and Figure 7 provides the evolution of its diameter. 

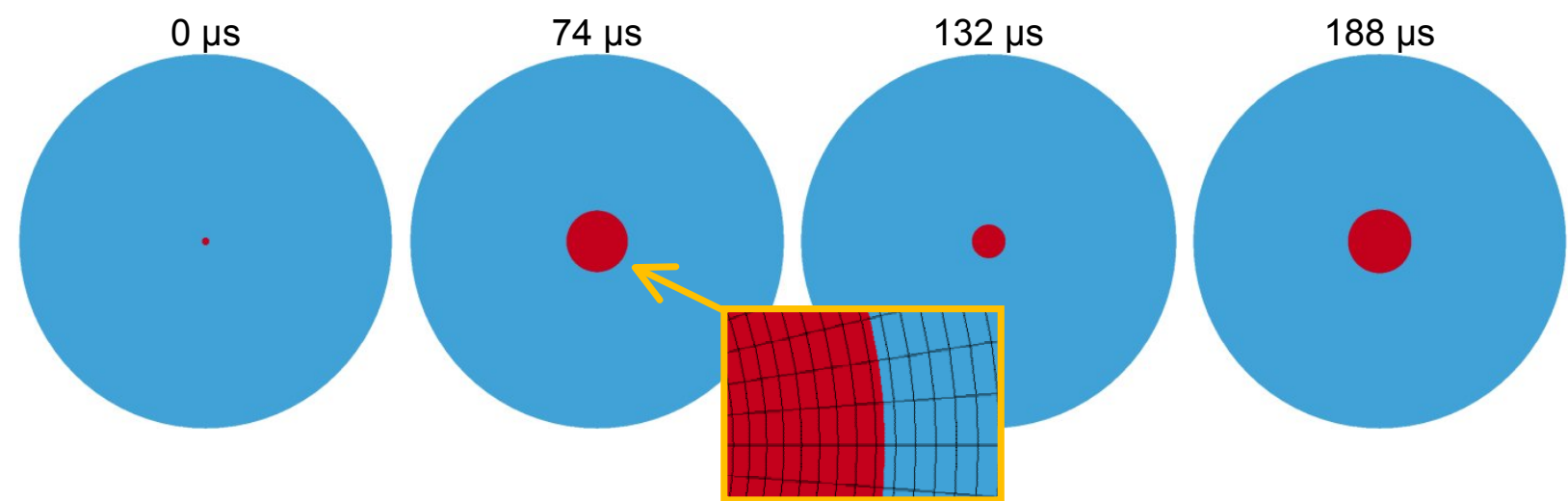

Figure 6. Pulsed discharge channel: an interface between the plasma channel and water moving through the mesh.

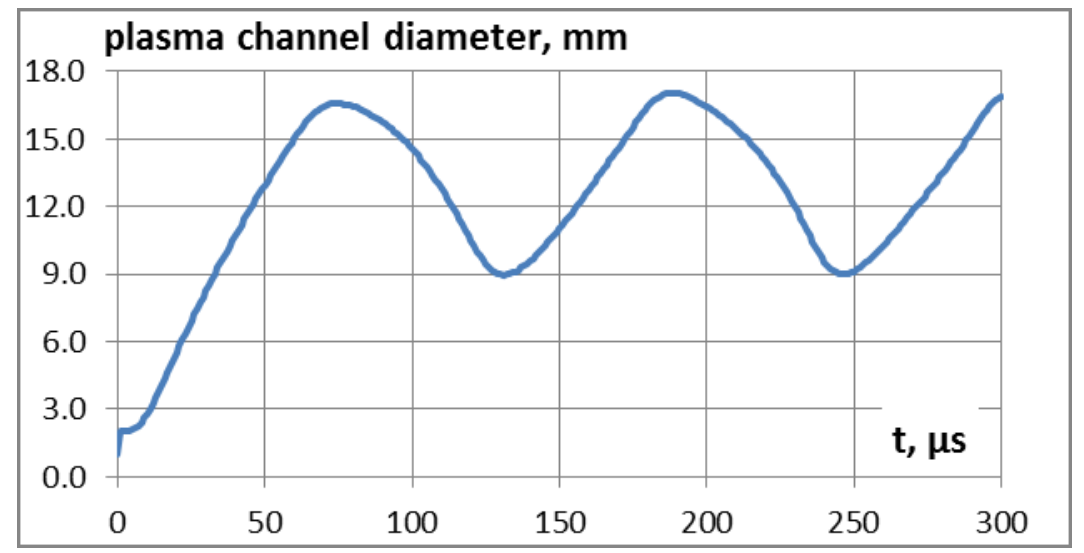

Figure 7. Diameter of discharge channel versus time.

Figure 8 shows the detailed distribution of the pressure in the cylindrical chamber. Each curve represents a different time slice showing the distribution of the pressure over the radial distance from the center of the chamber.

Between 5 and $20 \mu$ s the channel expands, and the pressure wave propagates from the center to the chamber wall. The pressure waves do not have a sharp front shape, since the energy is deposited in the channel not instantaneously but rather gradually over a time period of dozens of 
microseconds. This differs from explosive applications where the time of energy deposition is defined by the supersonic detonation process and typically lasts a few microseconds.

At $90 \mu \mathrm{s}$, the pressure at the wall is at a maximum and is comparable to the maximum pressure inside the channel. The channel finally starts to collapse, and then this process repeats itself, as seen at the moment of maximum central channel pressure at $130 \mu \mathrm{s}$ and then again at the chamber wall at $200 \mu \mathrm{s}$.

It worth noting that, although the simulation shows stable oscillations of the discharge channel, a similar length real channel inside a rigid small chamber will disintegrate into a cloud of small bubbles, and the second pressure spike will be significantly less than predicted by the simulation. The process of the channel disintegration can be indirectly inferred from the electrical current waveform shown in Figure 4.a where the current abruptly ends at $150 \mu$ s which corresponds the moment following the first collapse illustrated in Figure 7. Therefore, it should be indicated that the numerical model with perfectly sealed rigid walls provides predictions which correspond well to the experimental results up $150 \mu \mathrm{s}$. After $150 \mu \mathrm{s}$, due to the collapse of the plasma channel, the numerical predictions are no longer valid.

The maximum pressure of $82 \mathrm{MPa}$ at the chamber wall can be seen on the graph (Figure 8, $90 \mu$ s.) The experimentally measured value of $79.5 \pm 6.5 \mathrm{MPa}$ is in the good agreement with simulation. 

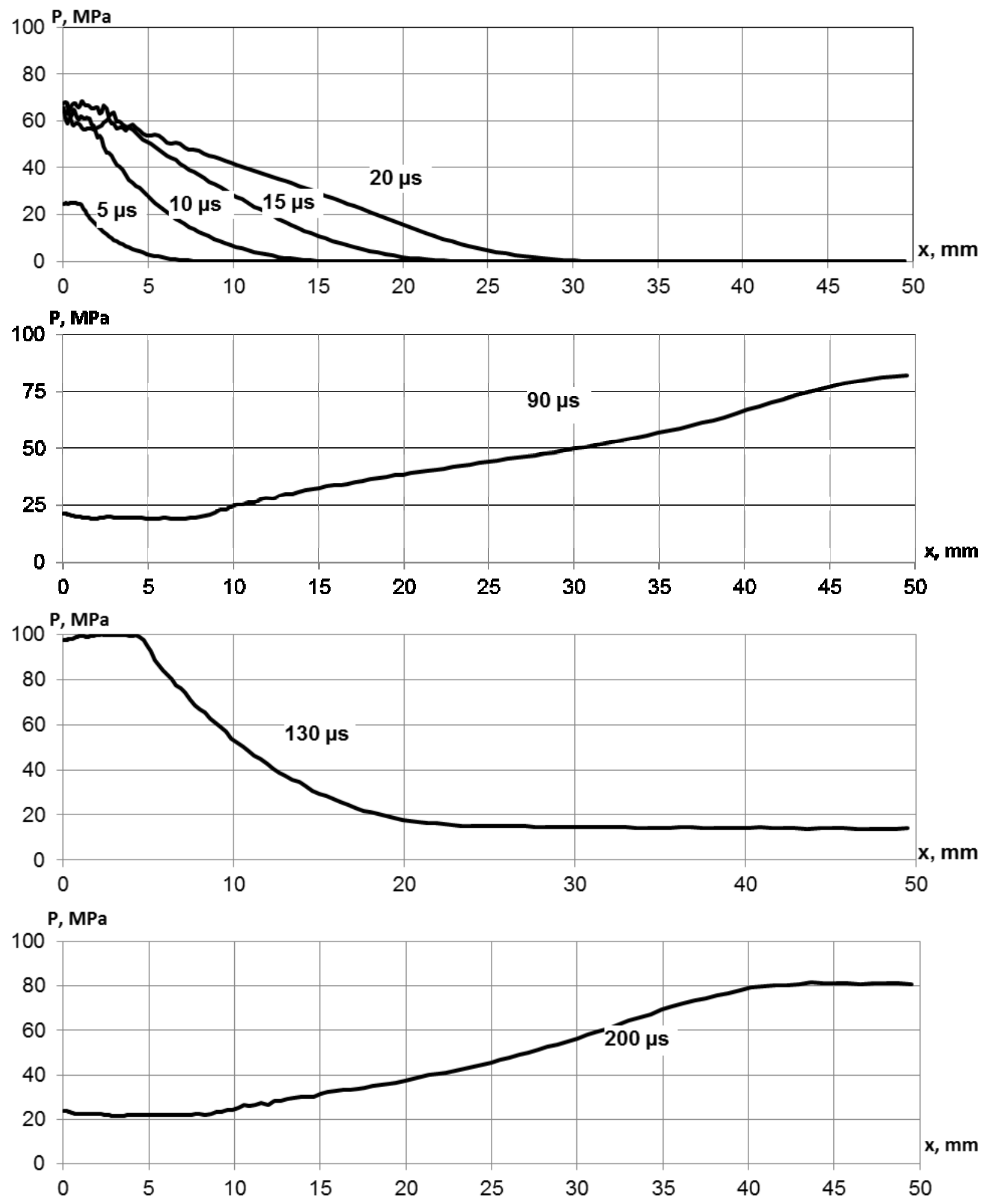
Figure 8. Distribution of the pressure in the cylindrical chamber at different times.

Horizontal axis $\mathrm{x}$ on the charts is the distance from the chamber center $(\mathrm{mm})$, vertical $\mathrm{P}$ - pressure.

$\underline{\text { Study of Influence of the Initial Channel Size and Density on Results }}$

The diameter of the discharge channel is a very important parameter, since it dictates the size of the smallest elements of the numerical mesh which in its turn defines the number of elements and the time integration step. Defining the acceptable diameter of the channel without affecting the accuracy of the simulation was the purpose of this study.

Using the simplified cylindrical chamber model, additional research was performed to estimate the influence of the initial channel radius and the initial channel density on the numerical results. Below, an estimate is presented that yields an acceptable range of variation of these parameters until they start affecting the results.

Table 1 shows the effect of initial radius variation on maximum pressure. The radius is varied in the range $r_{c h 0}=[0.15-20.0] \mathrm{mm}$. The following dimensionless parameter is used for the estimation

$$
\gamma_{r}=\left[p_{m}(0.15)-p_{m}\left(r_{c h 0}\right)\right] / p_{m}(0.15),
$$

where $p_{m}(0.15)$ - the maximum pressure at the wall during the first impulse for an initial channel radius of $0.15 \mathrm{~mm}$ (in the time interval $t \in[0-150] \mu \mathrm{s}$ ).

\section{Table 1}

Numerical effect from initial channel radius on the maximum pressure at the wall

\begin{tabular}{llllllll}
\hline$r_{c h 0}, \mathrm{~mm}$ & 0.15 & 0.5 & 1 & 2 & 2.5 & 5 & 10 \\
\hline$\gamma_{r}$ & 0 & 0.0099 & 0.0153 & 0.0706 & 0.1038 & 0.3102 & 0.6517 \\
\hline
\end{tabular}

It can be seen that for a small enough initial radius $r_{c h 0} \leq 1 \mathrm{~mm}$, the numerical error is less than $1.5 \%$. Thus, the initial radius was defined as $1.0 \mathrm{~mm}$ because smaller channel diameters 
create meshing problems and significantly reduce the integration time step. It is worth noting, however, that changing the initial size of the channel requires adjusting the energy deposition input which is provided by the card *DEFINE_CURVE as referenced by the *EOS_LINEAR_POLYNOMIAL_WITH_ENERGY_LEAK card. This card provides specific power, i.e. the total power divided by initial volume of the channel, and therefore changing the channel volume requires recalculating this curve.

Table 2 shows that the effect of initial plasma density on maximum pressure within the range $\rho_{p 0} \in[10-10000] \mathrm{kg} / \mathrm{m}^{3}$ is negligible.

\section{Table 2}

Numerical effect from initial channel density on maximum pressure on chamber wall

\begin{tabular}{lllll}
\hline$\rho_{p 0}, \mathrm{~kg} / \mathrm{m}^{3}$ & 10 & 100 & 1000 & 10000 \\
\hline$p_{m}\left(\rho_{p 0}\right), \mathrm{MPa}$ & 80.72 & 80.88 & 80.04 & 80.02 \\
\hline
\end{tabular}

\section{Simulation and Experimental Verification of Pressure Distribution}

The experimental setup with a small volume conical chamber is shown in Figures 9 and 10. The blank is positioned on top of the chamber, and the die with a set of open cylindrical cavities is placed on top of it. Positioning the chamber below the blank does not require removing all the water before opening the chamber; however, any entrained air in the chamber accumulates near the surface of the blank, significantly reduces process efficiency and decreases both the uniformity and predictability of pressure distribution. These cavities can create substantial pressure distribution heterogeneity as observed in the initial stage of both this experiment and earlier by Vohnout et al. (2010). 
To eliminate residual air, a system of channels (shown in Figures 9.a and 9.b) was designed in such a way that air leaves the leveled chamber along the blank surface in a number of different radial directions through channels cut in the tool along the perimeter of the blank's surface. This approach eliminates air entrainment which can happen due to the slight inclination of the tooling. The radial channels merge into an annular channel outside the blank boundaries connected to the die drain. This system allows air movement without the possibility of entrainment because the air can only move horizontally or upward. To close the chamber's volume and to prevent a water leak between the die and the chamber, the sealing ring shown in Figure 9.a was employed.

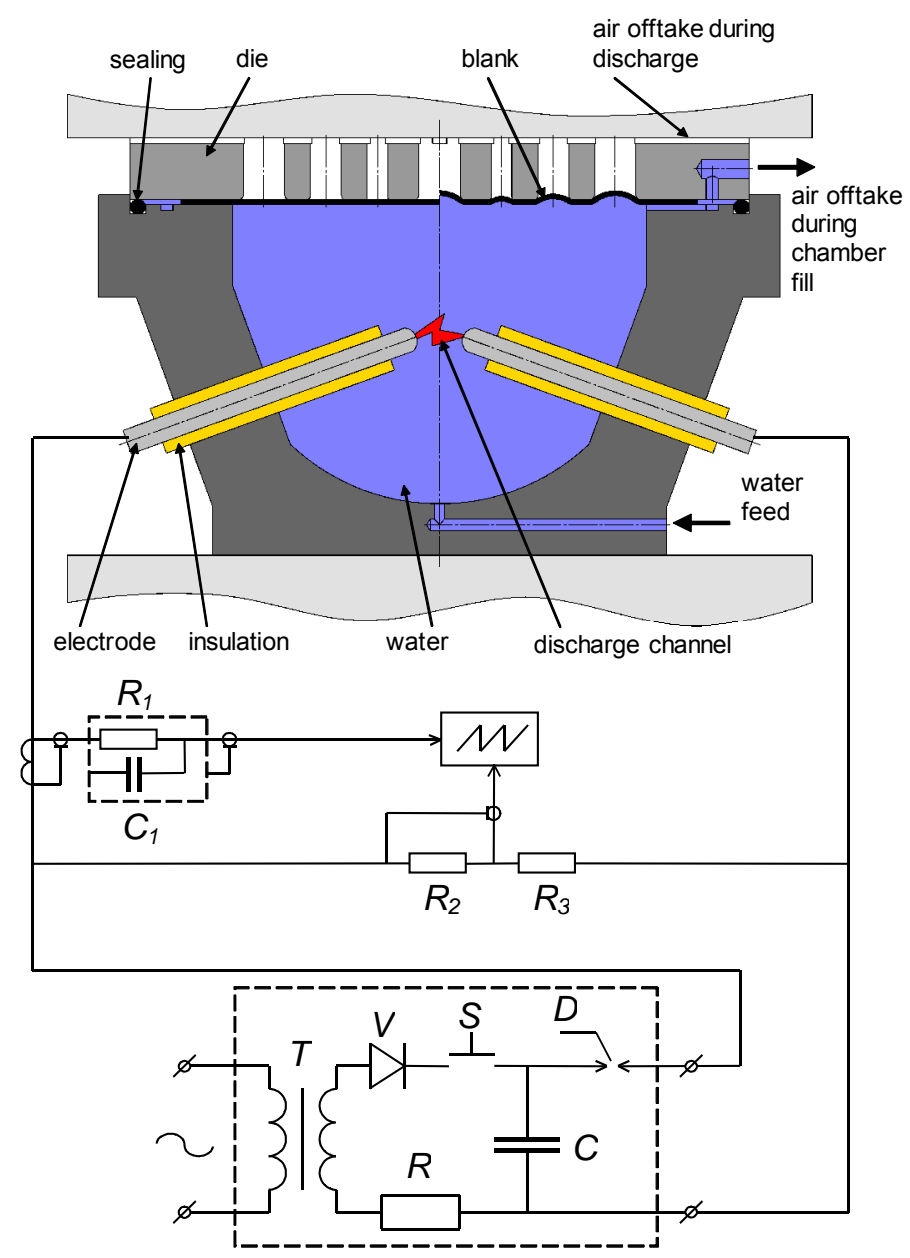

a)

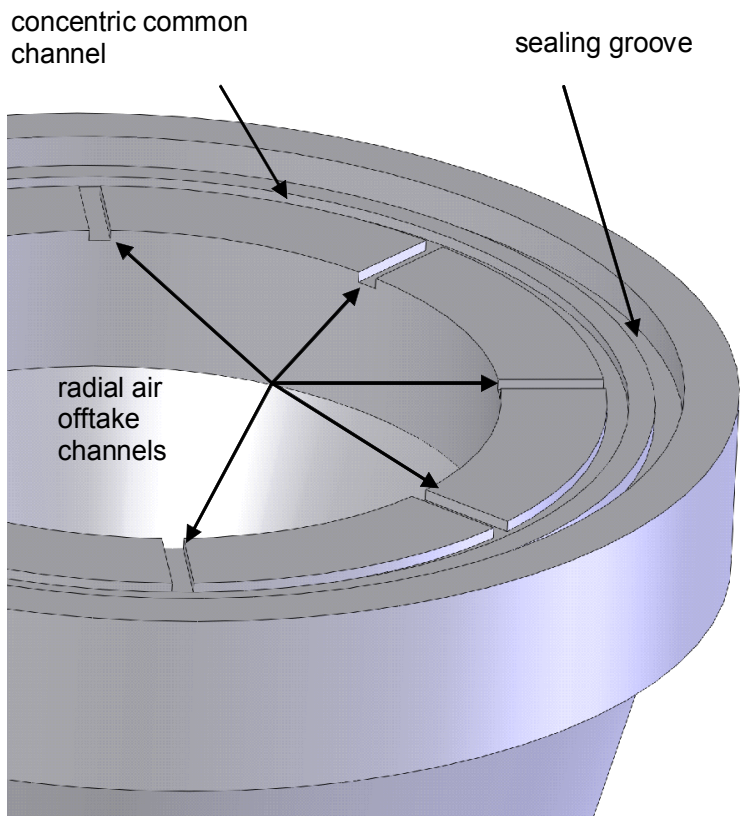

b) 
Figure 9. Experimental tooling: a - discharge chamber connected to the pulse generator and the measuring circuit of discharge current and voltage; $b$ - chamber venting channels.

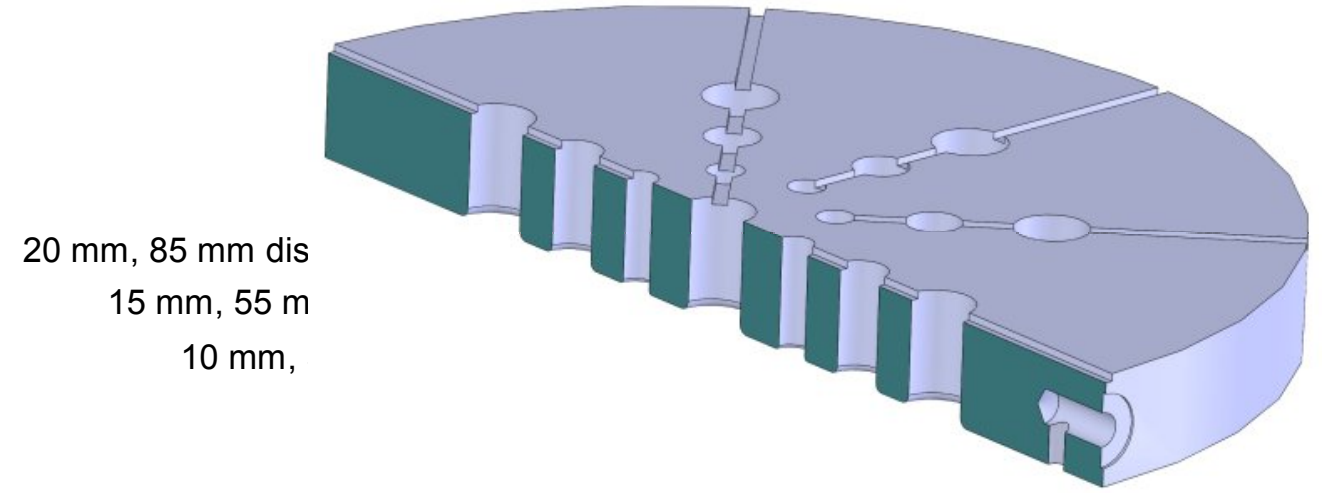

Figure 10. The die showing multiple free forming windows and channels for air removal during discharge.

To obtain pressure distribution heterogeneity information, at each of three different radial distances, a set of eight cylindrical cavities was machined into the tool to characterize the pressure using membrane measurement techniques.

Although it is possible to measure pressure distribution using a set of the membrane pressure sensors, as it is first described by Cole (1948), such sensors require calibration at quasistatic conditions and also require using relatively thin blank material along with the appropriate diameters of cylindrical cavities to minimize the effect from inertia forces and influence of material bulging on the wave picture. Still, there is the effect from the strain-rate sensitivity of blank material which is impossible to eliminate. Therefore, the focus was shifted from measuring the pressure distribution to comparing the simulation result with experimental data assuming that both simulation and experiment will naturally include all major factors

The scheme of cavities placement is shown in Fig. 10. The tool had holes in the following configuration: at a $30 \mathrm{~mm}$ radius eight $10 \mathrm{~mm}$ diameter holes; at a $55 \mathrm{~mm}$ radius eight $15 \mathrm{~mm}$ 
diameter, holes; and at an $85 \mathrm{~mm}$ radius, eight $20 \mathrm{~mm}$ holes. A single hole of $20 \mathrm{~mm}$ in diameter was placed at the center of the die. The "sensor" holes had fillets of 1, 2, and $2.5 \mathrm{~mm}$ radius in the 10,15 , and $20 \mathrm{~mm}$ cylindrical cavities, respectively.

The discharge circuit had capacitance $C=160 \mu \mathrm{F}$, resistance $R_{0}=0.0082 \mathrm{Ohm}$, inductance $L_{0}=2.16 \mu \mathrm{H}$, voltage range of $U_{0} \in[10-15] \mathrm{kV}$, and initial inter-electrode distance of 13.2 $\mathrm{mm}$.

At low voltages, the blanks did not show easily identifiable deflections in the smallest $10 \mathrm{~mm}$ diameter cavities while at the highest voltages, they exhibited splits in the $20 \mathrm{~mm}$ diameter cavities. Therefore, the optimal voltage was determined to be $13 \mathrm{kV}$.

The energy deposition in the discharge channel $N(t)$, which is used later as a key parameter in the computer simulation, is obtained by measuring pulse current $i(t)$ voltage $u(t)$ across the electrodes and integrating the resulting RC circuit.

The example of the blank made of IF steel $0.8 \mathrm{~mm}$ thick formed at $13 \mathrm{kV}$ discharge voltage is shown in Fig. 11.

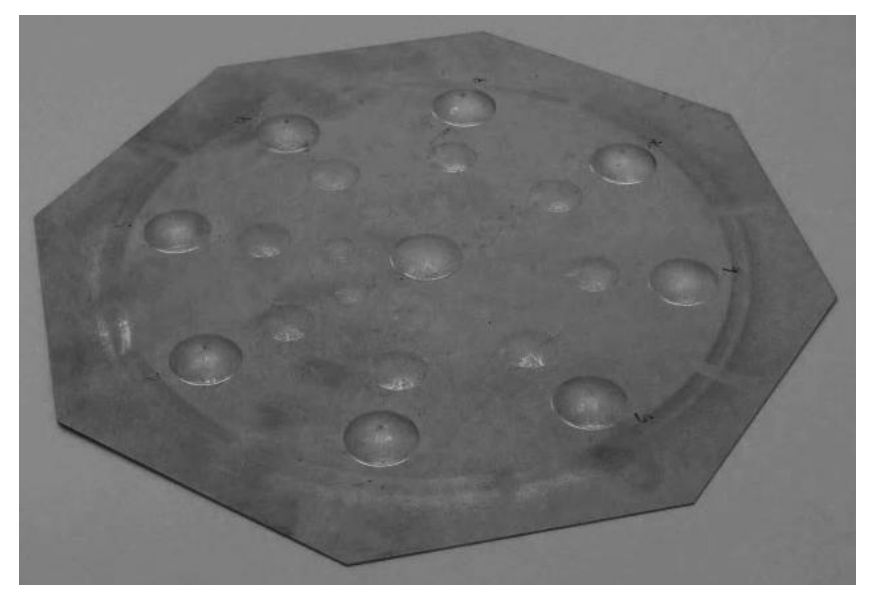

Figure 11. IF steel blank formed in the testing chamber using a $13 \mathrm{kV}$ charging voltage $\left(U_{0}\right)$. 
Table 3 shows all eight deflection values from the cavities at the same radius measured by a height gauge and averaged.

Table 3

Results of one discharge at $13 \mathrm{kV}$

\begin{tabular}{llll}
\hline diameter of the cavity, $\mathrm{mm}$ & 20 & 15 & 10 \\
\hline deflection, $\mathrm{mm}$ & $4.81 \pm 0.03$ & $2.05 \pm 0.03$ & $1.04 \pm 0.04$ \\
\hline
\end{tabular}

The results indicate that no significant difference in deflection exists among the cavities at the same radius from the die center. The level of heterogeneity is no more than $4.5 \%$ in the worst case and typically less than $2 \%$. It allows to conclude that a significantly larger level of heterogeneity observed in previous experiment was caused by residual air, the factor that was eliminated in this experiment.

The experimental setup was simulated using the ALE multi-material fluid formulation as described above. In the conical chamber, the discharge channel at the beginning of the process was small relative to the electrodes. Figure 12 shows the results of simulation of a discharge between two parallel electrodes: although the channel initially has the shape of an elongated cylinder, it very quickly starts to expand to become a sphere
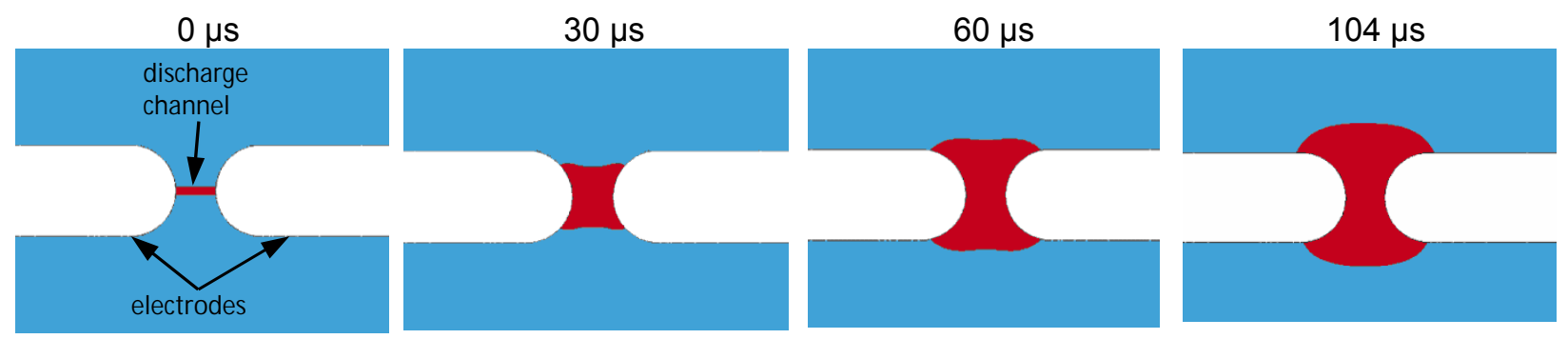
Figure 12. Results of simulation of discharge channel expansion between parallel electrodes.

In addition, the electrode volume in most chambers is less than a few percent of the total chamber volume and thus has negligible effect on pressure distribution. Therefore, in the simulation of the conical chamber and other models, electrodes are not taken into account. Depending on the model, the initial channel is meshed as a sphere of small radius or as just one element.

The material used for the blank is $0.8 \mathrm{~mm}$ IF steel which had very similar stress-strain curve as in Simunovic (1999). Therefore, it was considered appropriate to use the following workhardening and strain-rate sensitivity data for IF steel developed by Simunovic (1999). The original data on strain-dependent hardening are shown on Figure 13.

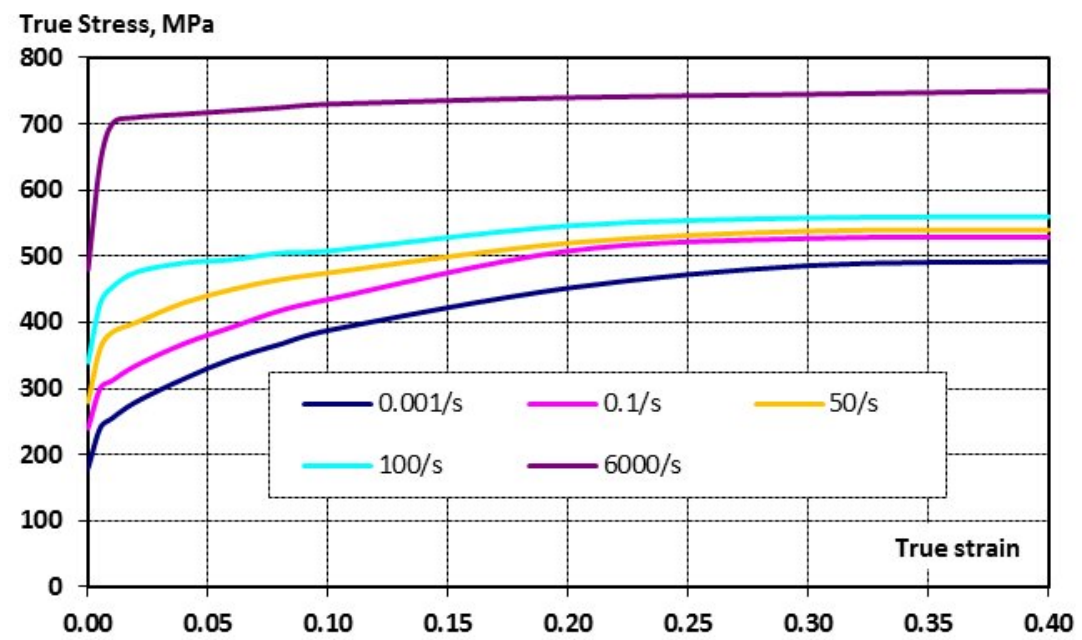

Figure 13. Strain-rate dependent hardening curves for IF steel according to Simunovic (1999). 
Since these data cover broad range of strains and strain-rates, the material model was defined using tabulated data in *MAT_PIECEWISE_LINEAR_PLASTICITY, when the curves are used directly as a set of tables, and interpolation between them is done by LS-DYNA internally.

The type of contact between the blank and the die is *CONTACT_SURFACE_TO_SURFACE.

Although the metal forming part of the problem is relatively simple and consists of about ten thousand elements, the mesh for the whole problem has more than four million ALE vacuum elements because of the requirement that ALE elements must be about the same size as contacting elements of Lagrangian structures.

The results of simulation of a $13 \mathrm{kV}$ discharge in a conical chamber are shown in Figure 14. The initial plasma bubble formation with subsequent expansion, propagation and shock wave reflection are clearly visible. The wave picture is clearly recognizable until the reflection occurs $(10 \leq t \leq 50 \mu \mathrm{s})$. After that the interference between reflecting waves creates a complex picture. At the same time the deformation of the blank begins. At the end of the simulation time, the channel collapses and starts disintegrating (its shape becomes unstable.) 

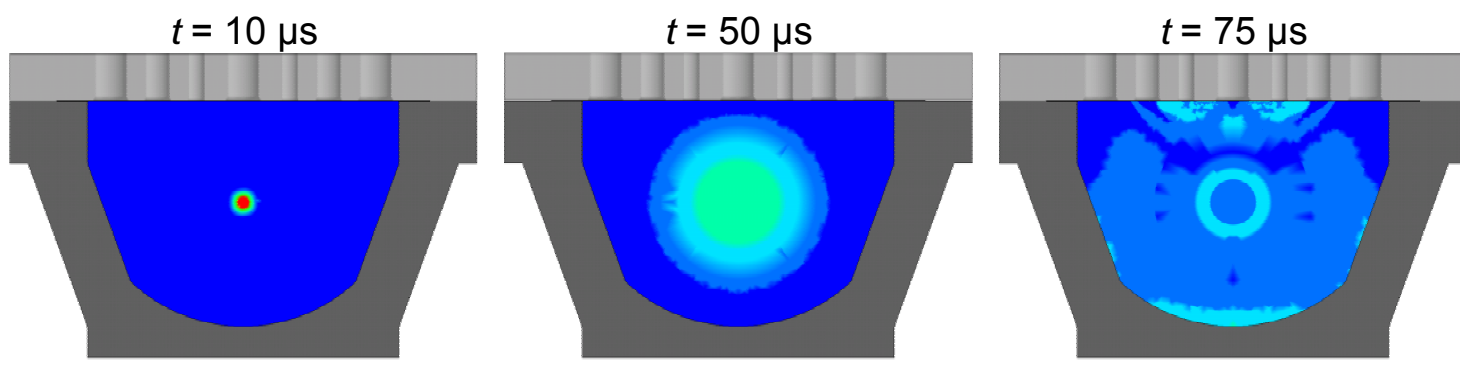

$\mathrm{kPa}$

$5.0 \mathrm{e}+4$

$4.5 \mathrm{e}+4$

$4.0 \mathrm{e}+4$

$3.5 \mathrm{e}+4$

$3.0 \mathrm{e}+4$

$t=125 \mu \mathrm{s}$

$t=150 \mu \mathrm{s}$

$2.5 e+4$
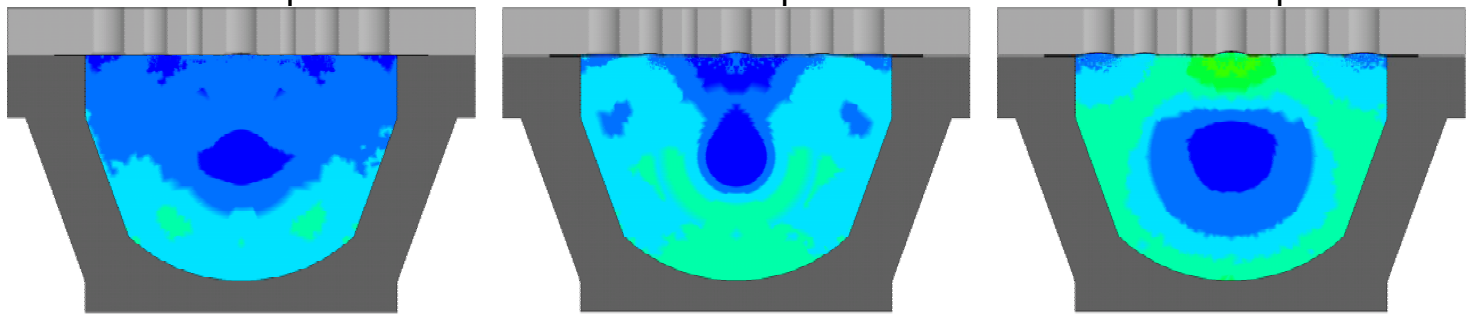

$2.0 \mathrm{e}+4$

$1.5 e+4$

$1.0 e+4$

$5.0 \mathrm{e}+3$

$0.0 \mathrm{e}+0$

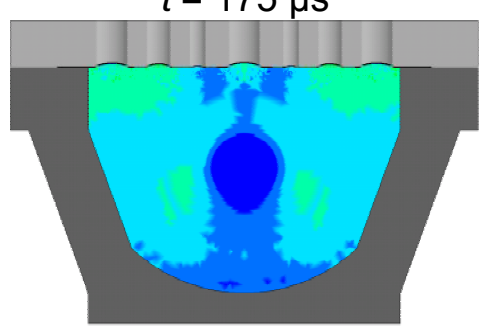

$t=200 \mu \mathrm{s}$

$t=225 \mu \mathrm{s}$
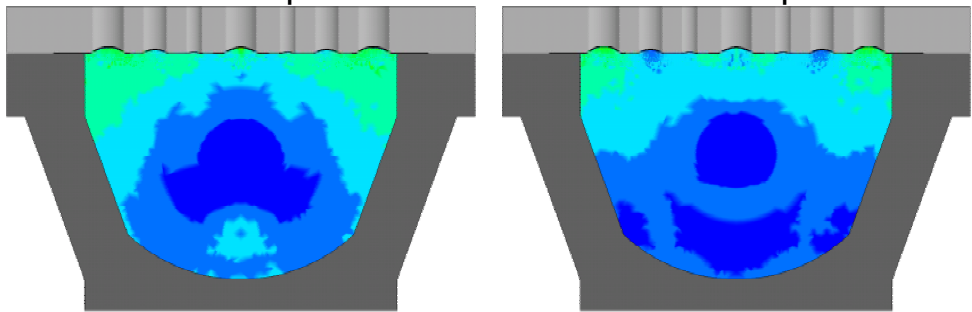

$t=275 \mu \mathrm{s}$

$t=300 \mu \mathrm{s}$
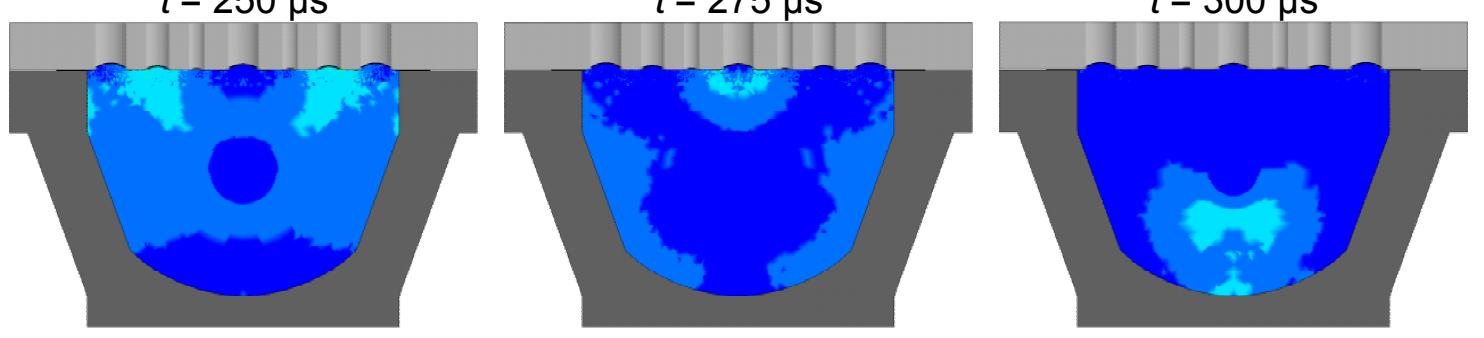

Figure 14. Example pressure distribution versus time simulation in the conical chamber for the charging voltage of $U_{0}=13 \mathrm{kV}$.

The evolution of predicted pressure at different chamber locations is shown in Figure 15. The pressure in the discharge channel at given parameters can reach $100 \mathrm{MPa}$, but at the surface of the blank it does not exceed 15-20 MPa. 

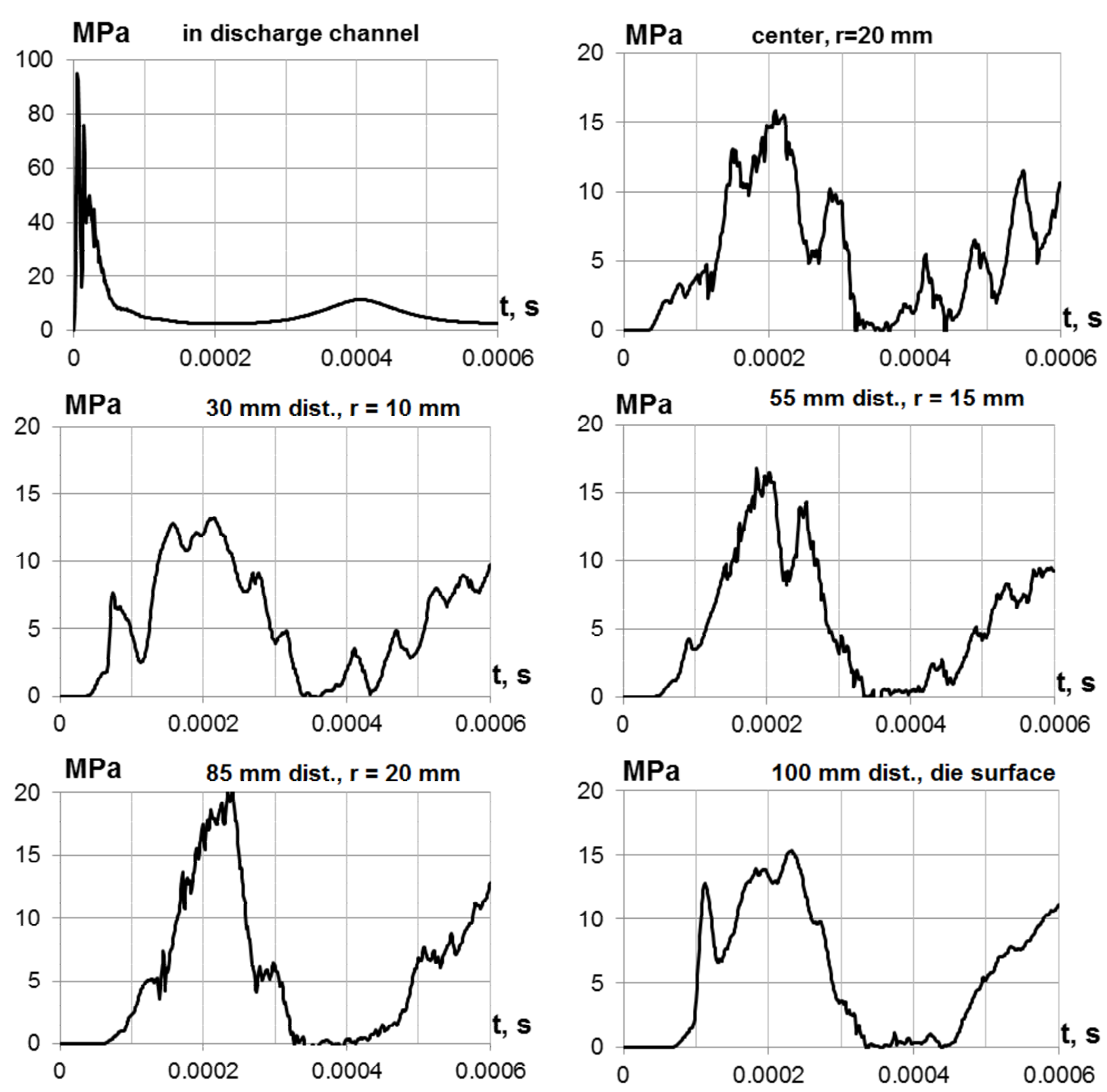

Figure 15. The pressure in the chamber at different points on blank surface.

The charging voltage is $U_{0}=13 \mathrm{kV}$.

The progress of the blank deformation in terms of moving the central point of each bulge is shown in Figure 16. Even though the pressure has several local maximums, the first pressure spike is always the highest, and the depth of the bulges grows only during the first pressure wave 
while in subsequent spikes, pressure is lower because of increasing the volume of the liquid due to the blank deformation.

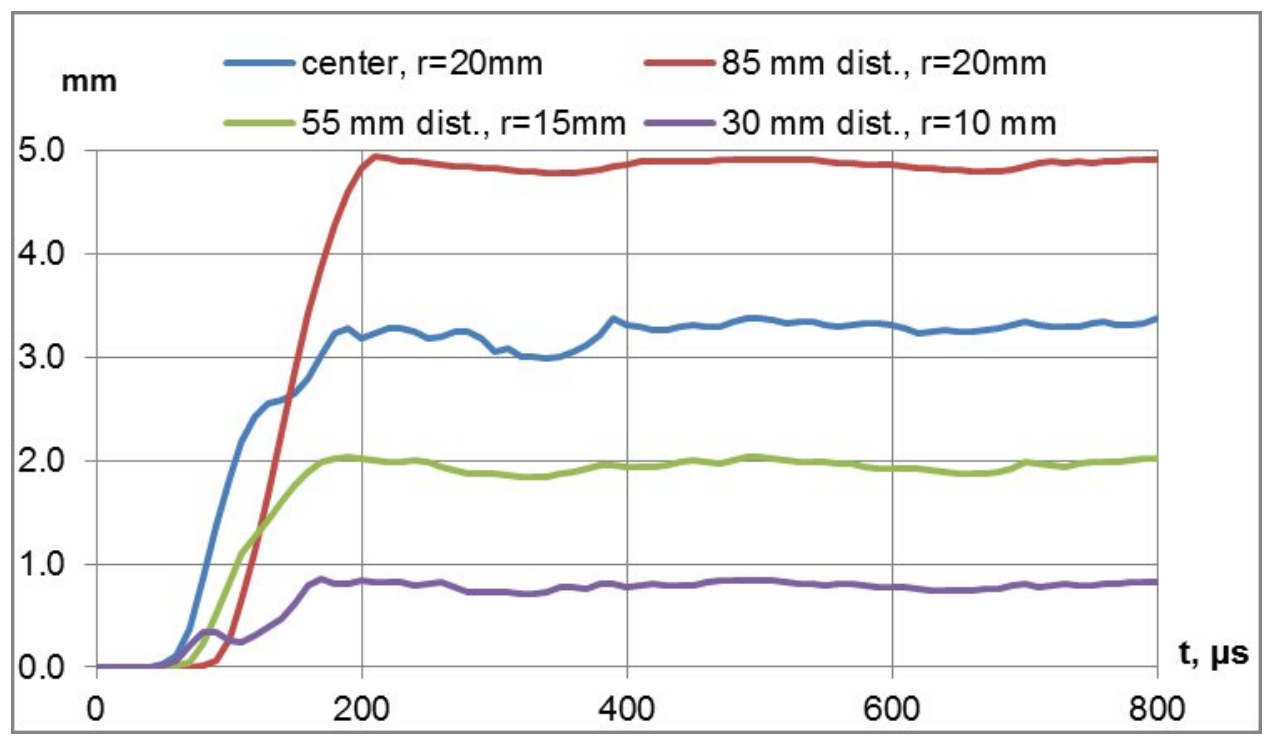

Figure 16. Evolution of bulge height during the discharge.

The comparison of numerical results and averaged experimental deflections for a $U_{0}=13 \mathrm{kV}$ discharge is shown in Table 4.

\section{Table 4}

Comparison of experiment data and simulation results on deflection of sheet into cylindrical cavities

\begin{tabular}{lllll}
\hline $\begin{array}{l}\text { hole diameter and } \\
\text { distance from the center }\end{array}$ & $\begin{array}{l}20 \mathrm{~mm} \\
\text { center }\end{array}$ & $\begin{array}{l}20 \mathrm{~mm} \\
85 \mathrm{~mm} \text { dist. }\end{array}$ & $\begin{array}{l}15 \mathrm{~mm} \\
55 \mathrm{~mm} \text { dist. }\end{array}$ & $\begin{array}{l}10 \mathrm{~mm} \\
30 \mathrm{~mm} \text { dist. }\end{array}$ \\
\hline measured deflection & $3.79 \pm 0.25$ & $4.78 \pm 0.32$ & $2.04 \pm 0.17$ & $1.03 \pm 0.06$ \\
\hline deflection from simulation & 3.38 & 4.90 & 2.01 & 0.82 \\
\hline
\end{tabular}




\section{Simulation of Electro-Hydraulic Forming of an Automotive Panel}

\section{$\underline{\text { Panel design, EHF tooling configuration and process parameters }}$}

The capabilities of developed numerical model were demonstrated for multidischarge EHF forming of a part shown in Figure 17 and incorporating features of a license plate pocket of a decklid. The discharge channel was positioned in the symmetry plane of the license plate illustrated by the dashed line.

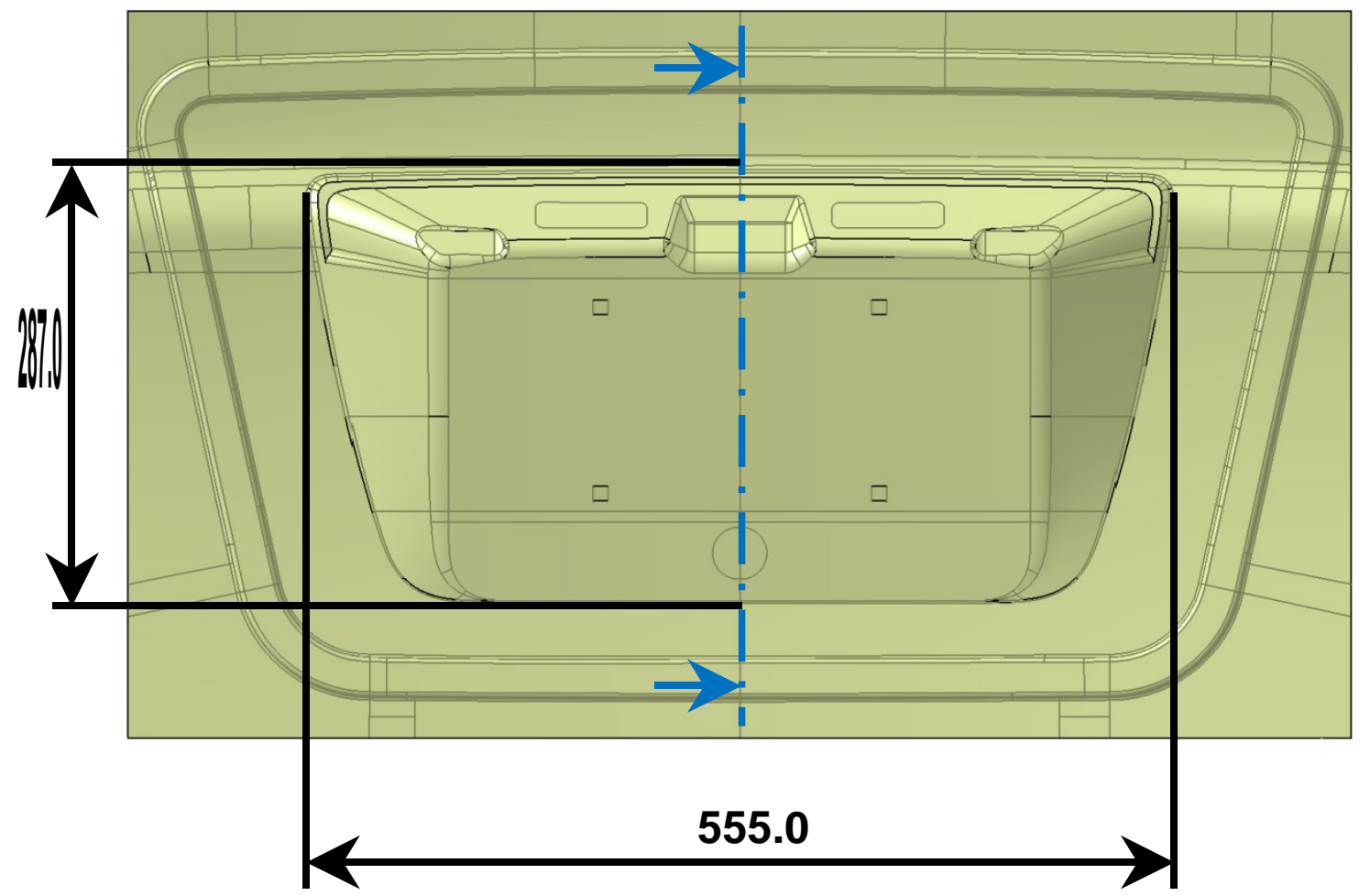

Figure 17. The design of the license plate pocket.

The sheet metal employed in this experiment was $1 \mathrm{~mm}$ thick DP500 steel sheet provided by Arcelor Mittal which had very similar stress-strain curve as in Baumer et al. (2008). Therefore, it was considered appropriate to use the following workhardening and strain-rate sensitivity 
parameters on DP500 steel according to Baumer et al. (2008). Original data are shown on Figure 18.

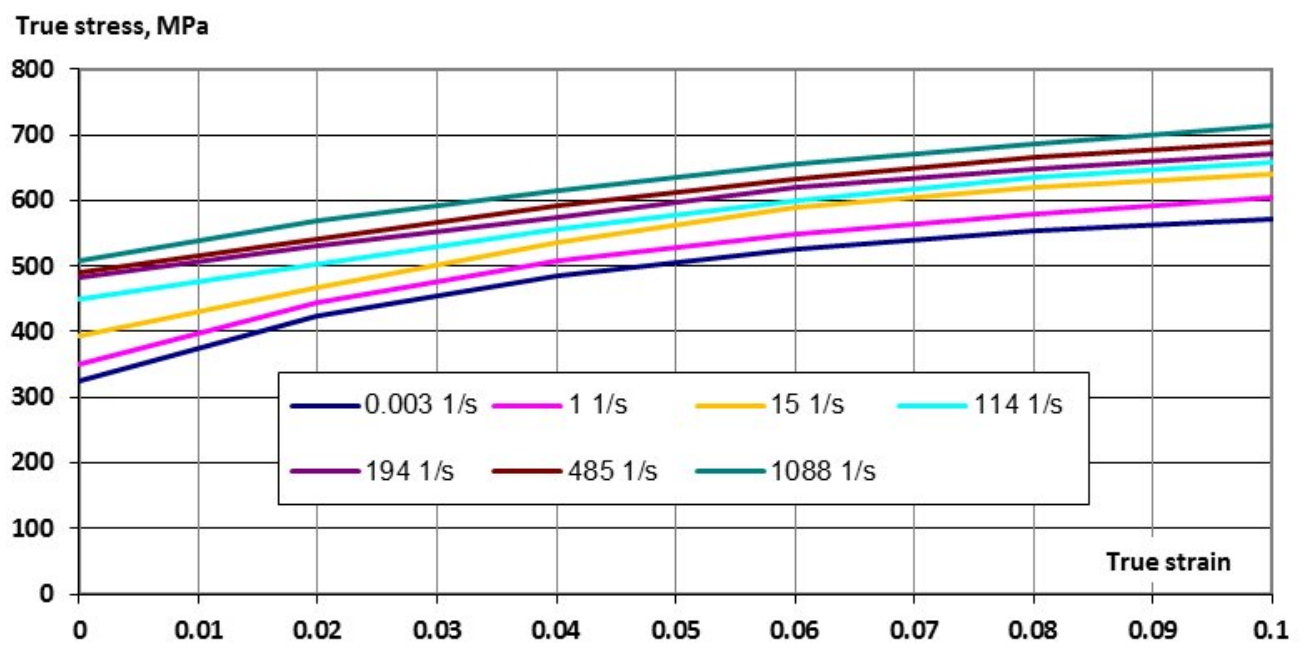

Figure 18. Strain-rate dependent hardening curves for DP500 steel according to Bäumer et al. (2008).

Based on these data, approximation was performed to obtain parameters of equation (8) that was used in the *MAT_PIECEWISE_LINEAR_PLASTICITY card to account for strain-rate sensitivity. Parameters were as follows: $\mathrm{C}=2.2 * 10^{4}, \mathrm{p}=2.618$.

The chamber designed for this part illustrated in Figure 19 had a volume of 11 liters and employed one pair of electrodes. 


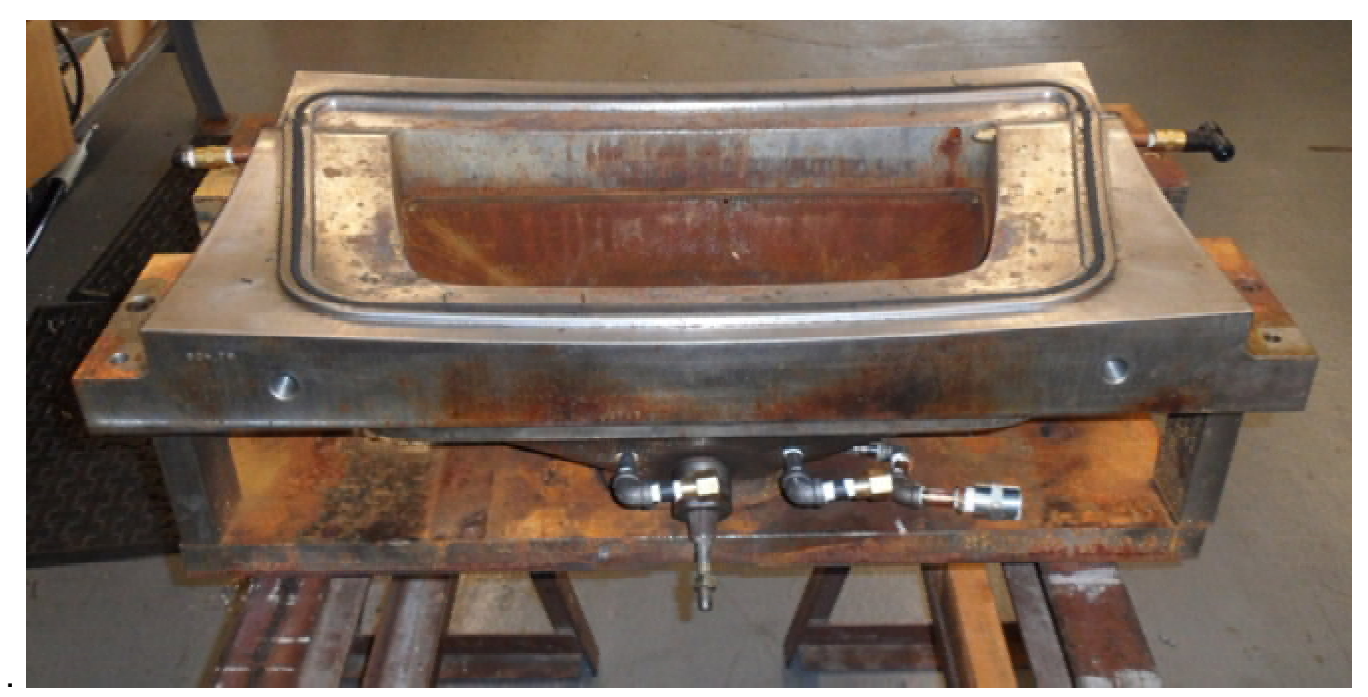

Figure 19. The discharge chamber for the license plate pocket tool.

The air inside the chamber and also between the blank and the die was removed before discharges using a vacuum pump. In such a configuration, EHF forming of the final shape by a single discharge is not appropriate because of the possibility of overloading/damaging the die in addition to non-optimal forming conditions. Therefore, three discharges $11 \mathrm{kV}, 11 \mathrm{kV}$ and $14 \mathrm{kV}$ of $200 \mu \mathrm{F}$ capacitor bank were performed sequentially.

In numerical simulation, the blank deformation and stresses were transferred from stage to stage using the capabilities of LS-PrePost postprocessor. One notable difference from the previously described simple problems is the need to automatically fill the space between the chamber and the blank with water multi-material group. The difficulty is that both the chamber and the blank had rather complex configuration with the shape of the blank changing gradually after each stage. This filling operation can be performed in LS-DYNA input using card *INITIAL_VOLUME_FRACTION_GEOMETRY where both the chamber and the blank meshes are referenced as enclosing surfaces. 
Measuring the discharge current and voltage and integrating these curves for every experiment is rather time consuming operation. Also, measuring voltage across the electrodes requires extra safety precautions. From the other hand, for the given configuration (i.e. the same pulse generator with the same connectors and the same discharge chamber with installed electrodes) the shape of the energy deposition curve is not changing significantly. Therefore, the initial integration was made for one set of parameters while for the rest of the experiments, only the amplitude of the energy deposition curve was adjusted in correlation with the charging voltage. The integration was performed for the discharge current and voltage curves shown in Figure 20a for $11 \mathrm{kV}$ discharge. The obtained energy deposition curve is provided in Figure $20 \mathrm{~b}$ which was used for all the others voltages with scaling proportional to the energy of the discharge.

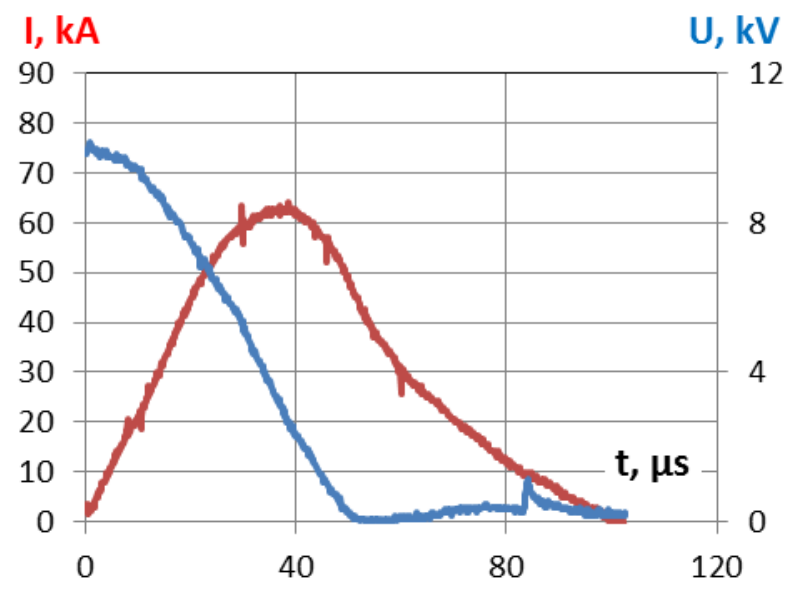

a)

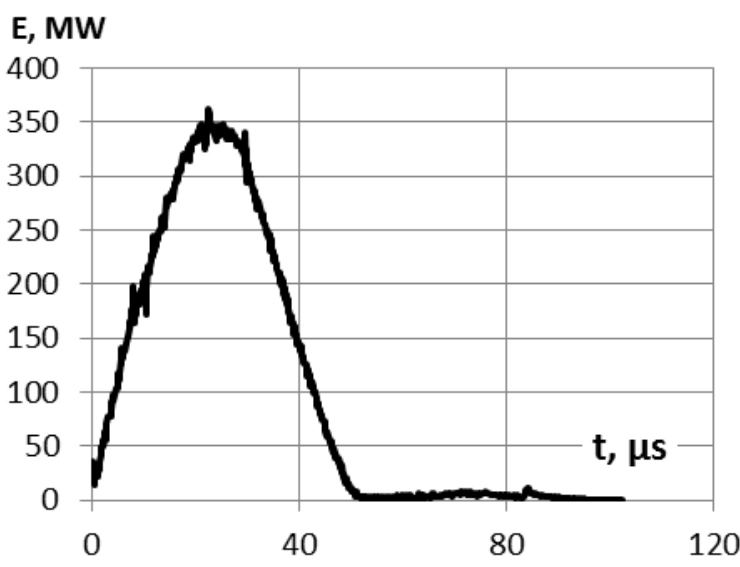

b)

Figure 20. Experimentally obtained current $i(t)$ and voltage $u(t)$ vs. time (a) and energy deposition law $N(t)$ (b) for the $11 \mathrm{kV}$ discharge in the discharge chamber for the license plate pocket tool. 


\section{$\underline{\text { Simulation Results and Discussion }}$}

Figures 21 and 22 show the simulation results for the first discharge. Figure 21 shows the progression of the channel shape and the deformation of the blank. Figure 22 shows the pressure distribution at different moments in time. Both Figures 21 and 22 are shown with the crosssection marked in Figure 17. The simulation results for the second and third discharges are very similar to the first discharge and are thus not shown. 


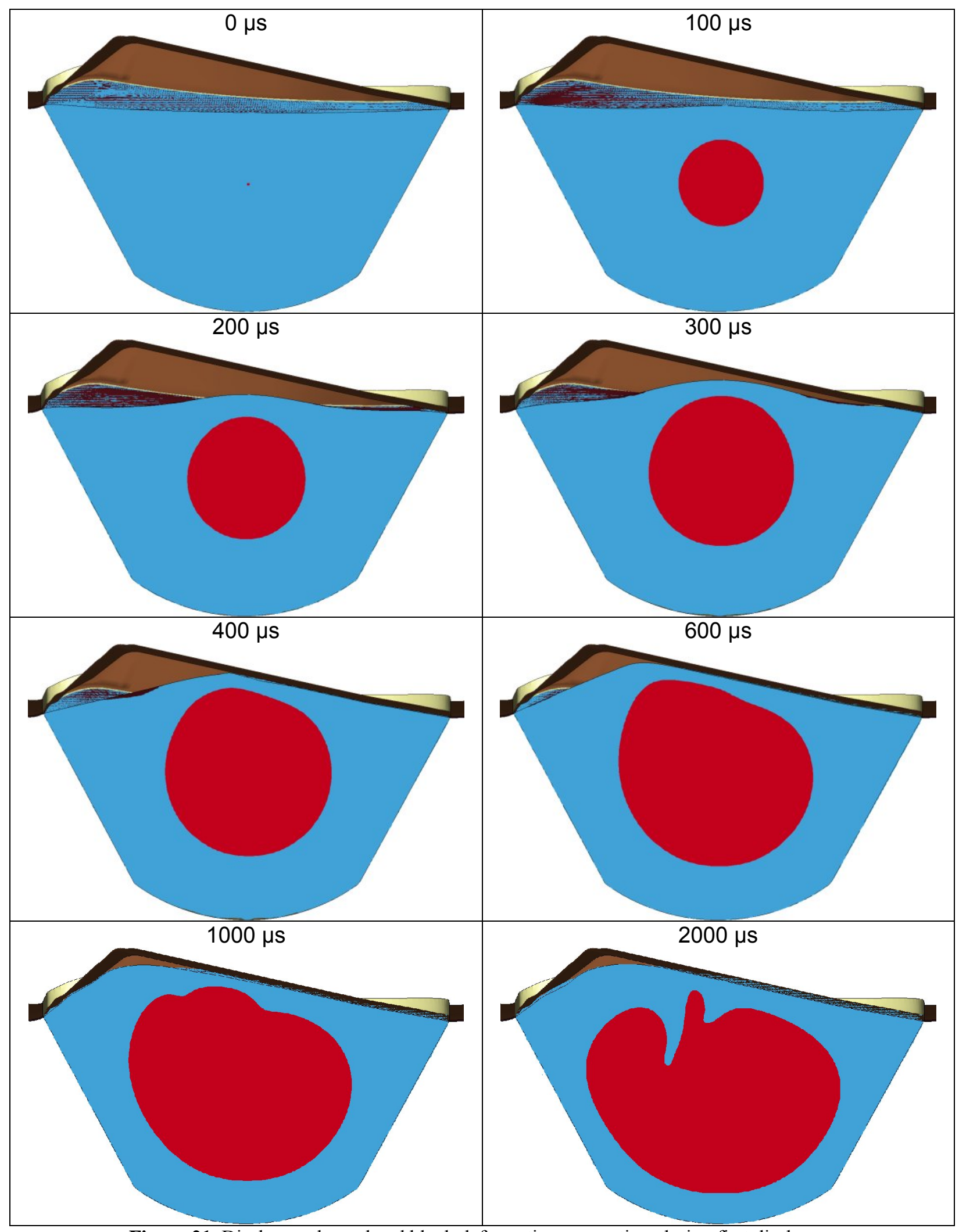

Figure 21. Discharge channel and blank deformation versus time during first discharge. 
Page 37 of 54 


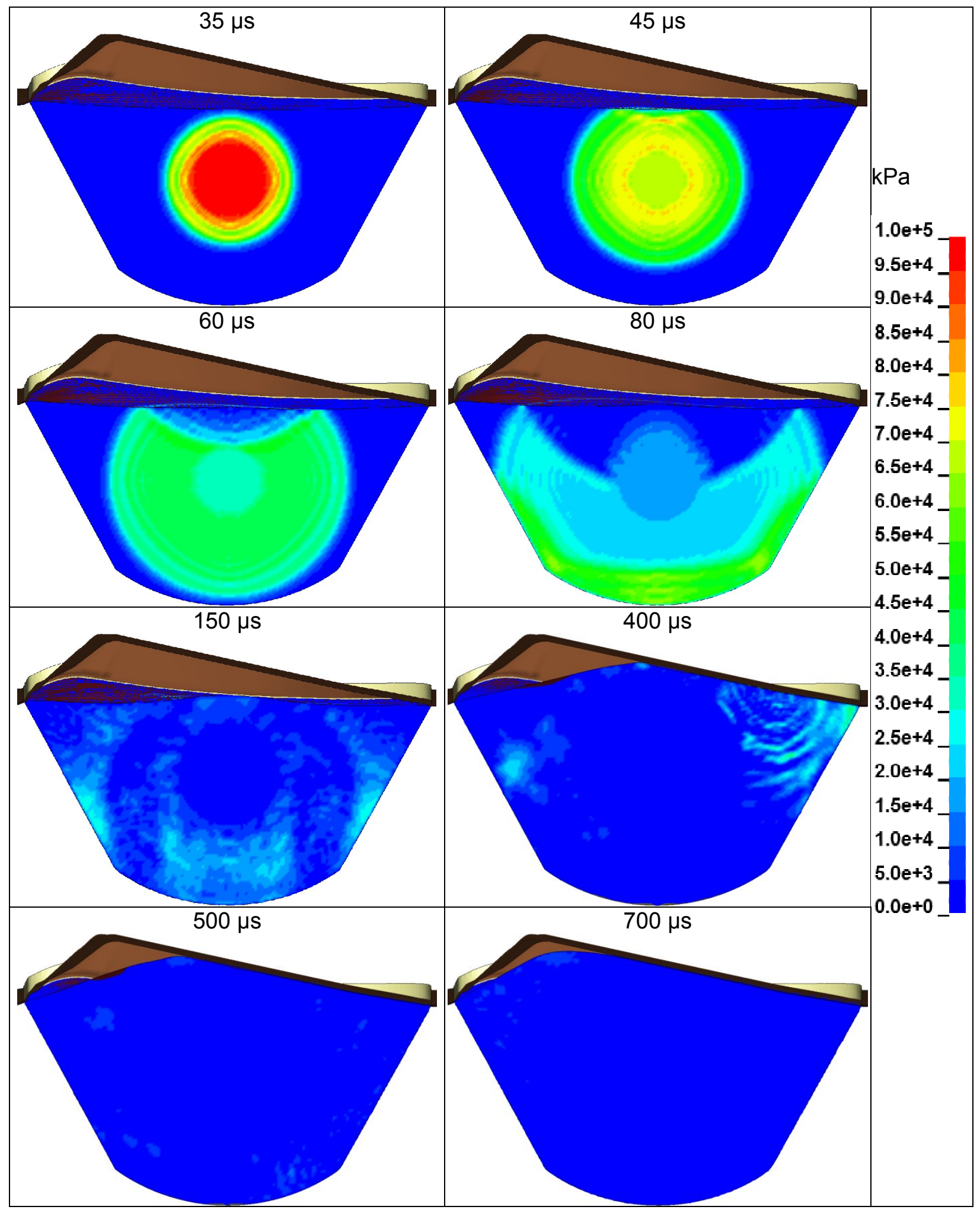

Figure 22. Pressure distribution at various times during the first discharge. 
The Figure 23 shows the simulated shape of the blank in comparison with experiment after each discharge.

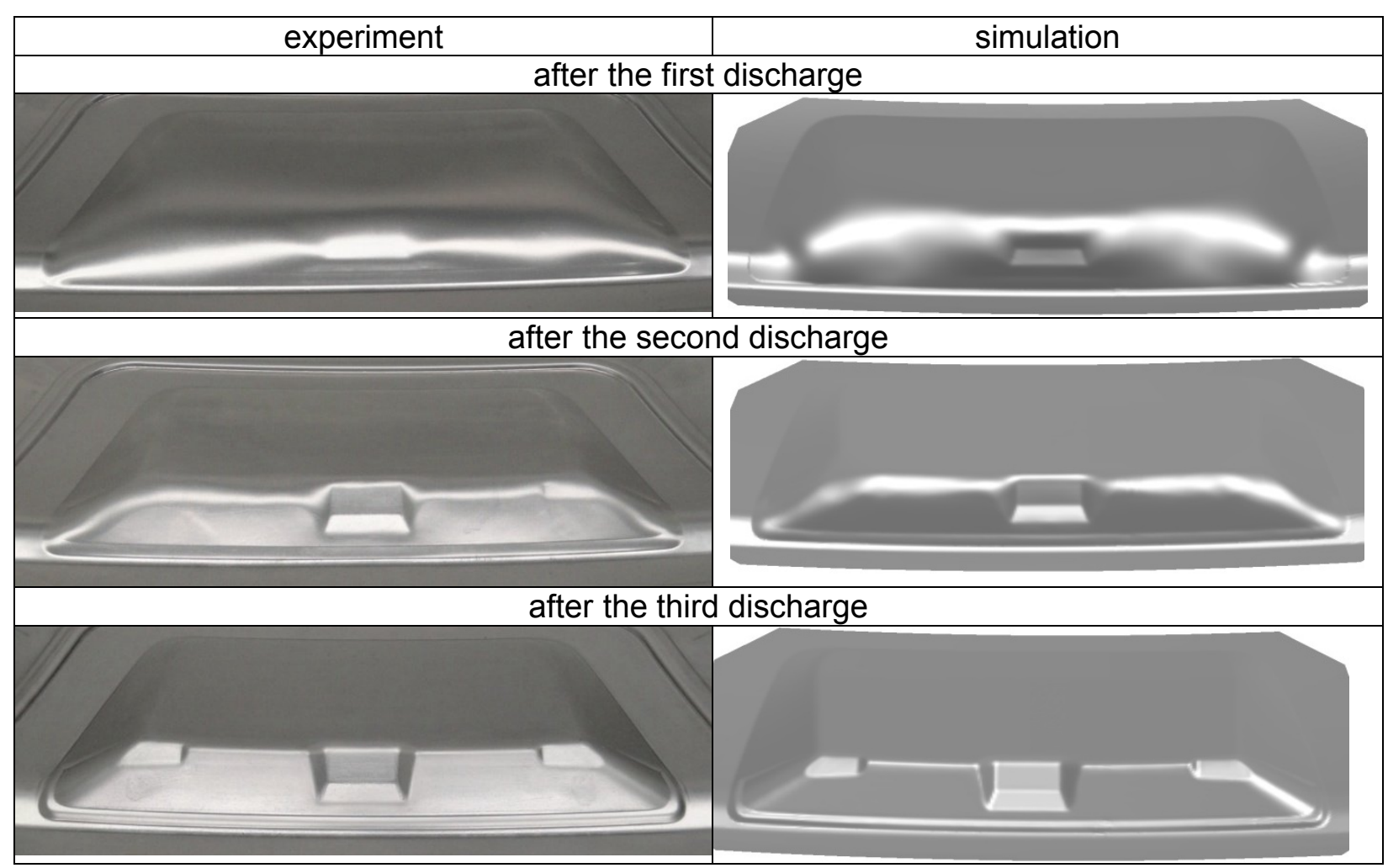

Figure 23. Comparison of blank geometry in both simulation and experiment.

A few observations can be made from the results of this simulation: after the first discharge, the simulation predicts larger deformations than the experiment, and, after the second discharge, the correlation is opposite. The final position of the blank after each discharge is defined by the total amount of work performed by the expanding channel during the forming process. Most likely, this error can be attributed to the employed simplified approach to determining energy deposited into the plasma channel which is based on a single calibrated energy curve and a total 
charging energy. It is worth noting though, that in practical usage of the developed simulation technique for designing the EHF technological process, these possible errors in determining the position of the blank during intermediate steps are not critical. The typical design approach is to simulate few discharges with different energies and to choose the most optimal sequence of discharges. Then, during the setup of the process, the actual energy of the discharge of the pulse generator on each step is adjusted to achieve the optimal final deformation preliminary defined in the simulation.

Next observation is that there are notable differences in the way the blank deforms compared to quasistatic hydroforming. Firstly, according to the quasistatic hydroforming simulation results (the simulation configuration is not described here) performed for the same blank into the same die, the static pressure required to completely fill the die exceeds $80 \mathrm{MPa}$. The minimum force required to hold a hydroforming chamber closed can be estimated by multiplying the part surface area (see Figure 16) by pressure and exceed 1200 tonnes. On the other hand, this part was successfully formed via EHF using just a 100 tonne press. Even if maximum pulse pressure in EHF reaches or exceeds that of the hydrostatic process, this is possible because the pressure pulse is applied over a few $\mu$ s and is not distributed uniformly over the blank's and chamber's surface. This perfectly illustrates one of the advantages of EHF technology: it requires less powerful (and less expensive) equipment than quasistatic forming methods.

The second difference from the quasistatic hydroforming is the dynamic character of deformation. The blank starts to deform in the area close to the discharge, and this bulge can be seen around the channel at $200 \mu \mathrm{s}$ in Figure 21. It is the result of pressure wave localization and is also observable in Figure 22. The comparison of the shape of the blank obtained by numerical simulation at similar phase of deformation in quasistatic and EHF process is shown in Figure 24. 
As it can be seen from Figure 24, the shape of hydrostatically formed blank is smoother, and the blank formed by EHF has a zone affected by discharge proximity. This effect has to be limited during the design process, since it leads to localization of deformation and waviness in the resulting blank surface or even to blank splitting in the area closest to the channel. To minimize this effect, the discharge energy should be appropriately balanced against the ratio of the initial distance from the channel to the blank to typical chamber dimensions. Increasing the distance between the blank and the discharge channel (with accompanying increasing of the chamber volume) will reduce the localization of pulse pressure (which is a positive factor) but, on the other hand, it also reduces the system efficiency because the wave pressure diminishes with increasing distance and with the increased liquid mass that must be moved. A decrease in the energy of particular discharges can also help to reduce the localization effects, but, because of the smaller deformation achieved during a single discharge, more discharges will be required to fill all the features of the die cavity. Such a design process can require a lot of iteration; therefore, having a reliable simulation tool is very important.

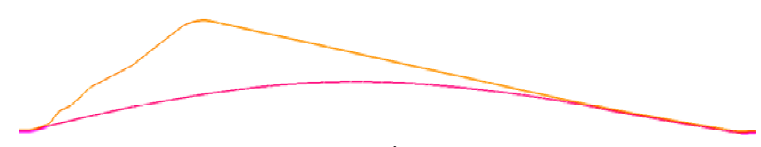

a)

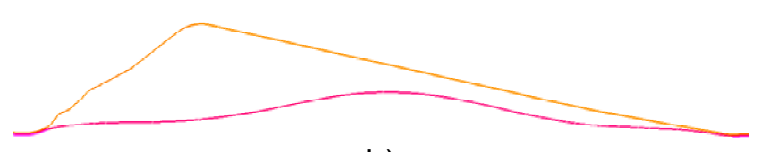

b)

Figure 24. Comparison of blank geometry during quasistatic (a) and EHF (b) hydroforming. Cross-section shown is the same marked in Figure 17.

One interesting possible solution to the deformation localization issue is to combine quasistatic hydroforming with subsequent EHF. The blank is first formed hydrostatically in the same chamber that is then used for EHF. The applied pressure cannot exceed the overall tonnage 
of the press clamping the EHF chamber to avoid opening of the tool. From the other hand, the pressure should be sufficient to move the blank away from the future discharge channel. Then, EHF discharges can be done safely with higher process efficiency.

The next observation is that, unlike the previous cases where a discharge happens in a relatively small chamber with mostly rigid walls, the volume of the chamber suitable for forming of full scale panels is relatively large, and the deformable blank can travel long distances. A significantly longer deformation process may take up to few milliseconds for the blank to stop moving in comparison with just 0.25 millisecond in the conical chamber. As Figure 21 shows, larger deflections also lead to a significant lower pressure level which effectively makes the problem similar to an incompressible fluid flow problem where the blank is deformed by a water flow rather than by a shock wave.

The long process duration, in addition to changing the contact conditions (including impact velocity and contact pressure), poses additional challenges to simulation stability and requires significant attention to the contact algorithm settings and model parameters. Although EHF process simulation changes in the advection method in *CONTROL_ALE card usually result in minor influence on the results (especially in small-volume chambers), some methods can cause numerical instability in long discharge simulation after hundreds of $\mu \mathrm{s}$. A stable working option for long duration processes is setting the parameter METH $=1$ (donor cell, Half-Index-Shift, first order accurate). Specifying the ILEAK $=2$ option in the FSI definition (card *CONSTRAINED_LAGRANGE_IN_SOLID), which prevents artificial penetration of fluids through Lagrangian structures, can cause numerical instability at the time when the process becomes a nearly incompressible fluid flow. Therefore, when possible, the value ILEAK $=0$ 
must be used as the safest variant, and only changed to 1 or 2 when fluid penetrates the blank or the die.

\section{Simulation of Electro-Hydraulic Calibration of an Automotive Panel}

Calibration of the formed panel is usually accomplished by the final discharge of the EHF forming sequence of the discharges. It usually serves dual purposes: 1)fill all the features of the die cavity by the material of the blank and obtain the indication that no more water can be added to the chamber; 2)eliminate or at least minimize the residual stresses in the formed part to minimize the springback after the tool is open. In fact, additional stretching at the end of the process by filling local features also helps to reduce the springback in addition to the pulsed stress relieving mechanism described by Golovashchenko et al. (2014). However, the main emphasis of this section is on getting a sufficient pressure to fill all the features of the die shape and designing EHF chamber for maximum energy efficiency and electrode life.

As mentioned above, the process of electro-hydraulic calibration is performed as a final operation to finish the last small part features. Therefore, the blank can be considered to be stationary, and the only important information is the maximum pressure achieved at the blank surface during the first (and most intensive) pulse wave at a few critical points on the part. Figure 25 shows these points where maximum pressure is required to completely fill the die. 


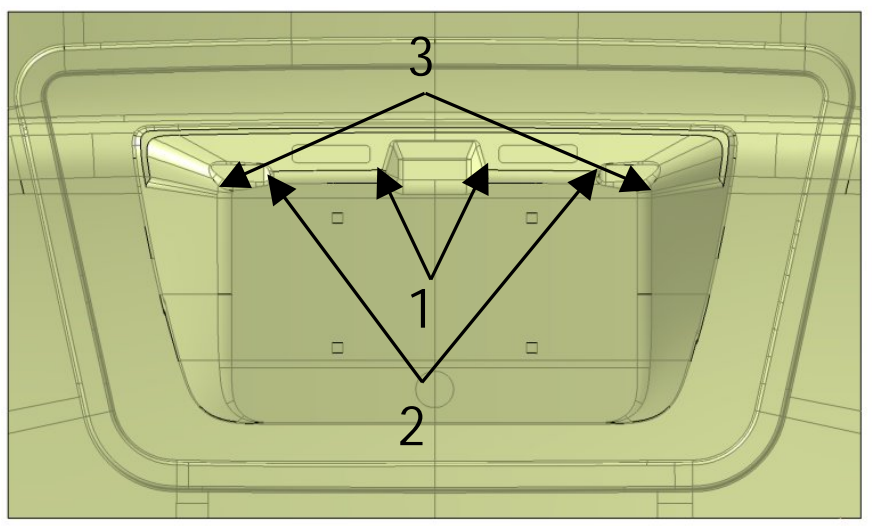

Figure 25. The most critical areas in the die cavity requiring the highest corner filling pressure. Symmetrical areas are marked in pairs as 1,2 , and 3.

Although the ALE technique is generally preferable for EHF simulation due to meshing simplicity and the ability to simulate long processes (up to a few ms), it is difficult to use it in this particular case. The critical corners require very fine meshing to accurately capture the pressure distribution and the small corner filling process. The ALE approach leads to a very significant number of ALE elements because of the requirement that ALE and blank mesh elements must be of similar size. Therefore, the Lagrangian approach is used for this analysis.

\section{Design of the Model}

The maximum pressure is achieved before the start of channel collapse, and, in general, the deformation of the fluid is moderate because the blank is stationary which eliminates the problem of the mesh distortion. On the other hand, unlike the ALE mesh, the Lagrangian mesh can be configured with variable mesh density. In this model, only the mesh around the critical areas and around the initial discharge channel is refined while the rest of the model is meshed with moderately sized elements suitable for capturing smooth pressure waves. For additional simplification of the model, the mostly steady blank is not taken into account, and the fluid is 
considered to be fully enclosed by a rigid chamber which is simulated through boundary conditions.

Figure 26 shows the initial geometry of the chamber along with the suggested meshing strategy details for the Lagrangian approach. The simulation can be performed using regular desktop computer, whereas a comparable ALE model requires a supercomputer cluster. Figure 27 shows the modified chamber geometry which is used for comparison: the overall volume was decreased, and the discharge channel was moved closer to the critical areas where the highest pressure level is required to fill the features of the shape of the die.

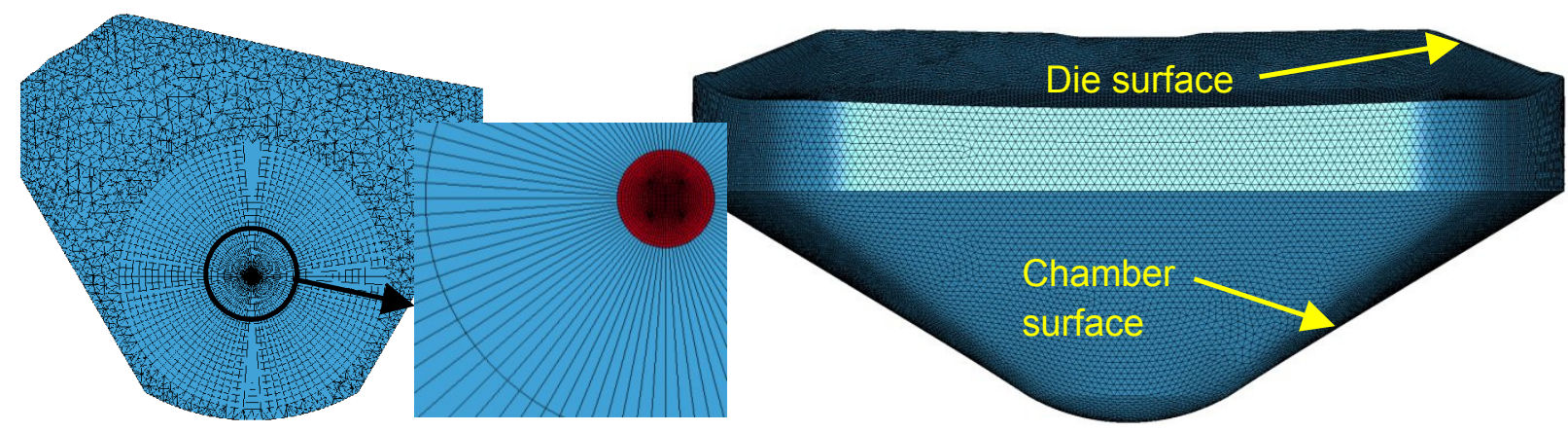

Figure 26. Initial EHF chamber configuration for forming of the license plate area designed prior to the development of the EHF process numerical model.

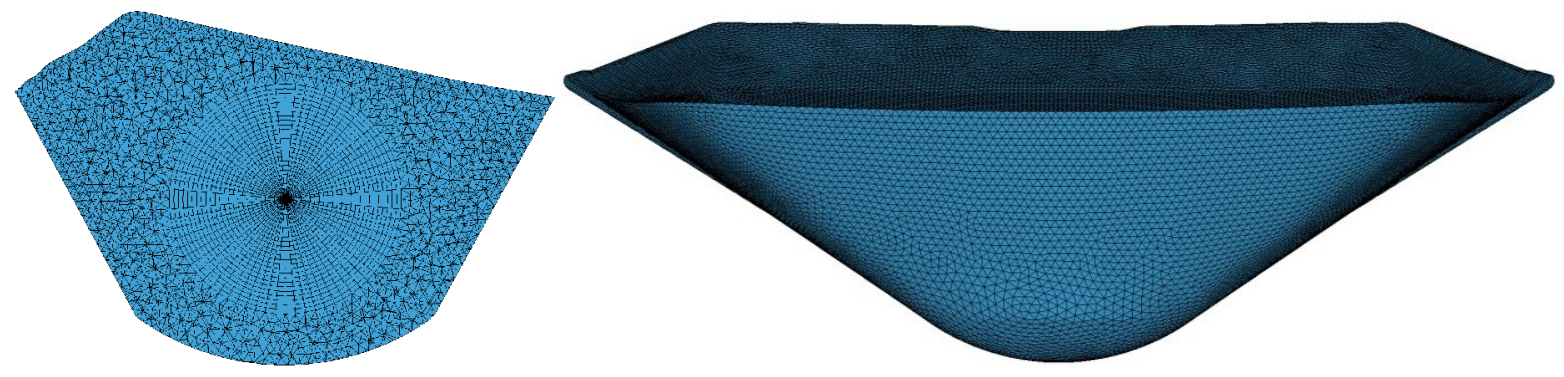

Figure 27. Modified configuration of the EHF chamber reducing the volume of the chamber and the distances to the critical areas. 
The results of simulation for the two geometries using the same energy input are shown in Figure 28, 29, and 30. The analysis shows that reducing the chamber dimensions and distance from the channel to the blank significantly increases the maximum pressures.

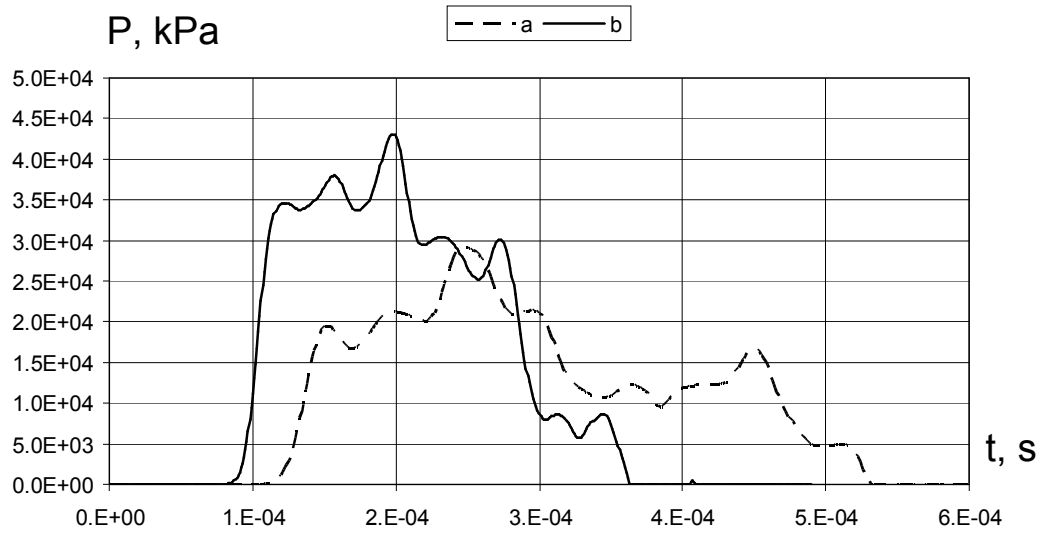

Figure 28. Results of numerical simulation for critical area 1 where "a" is the initial chamber design from Figure 26 and "b" is the new chamber design from Figure 27.

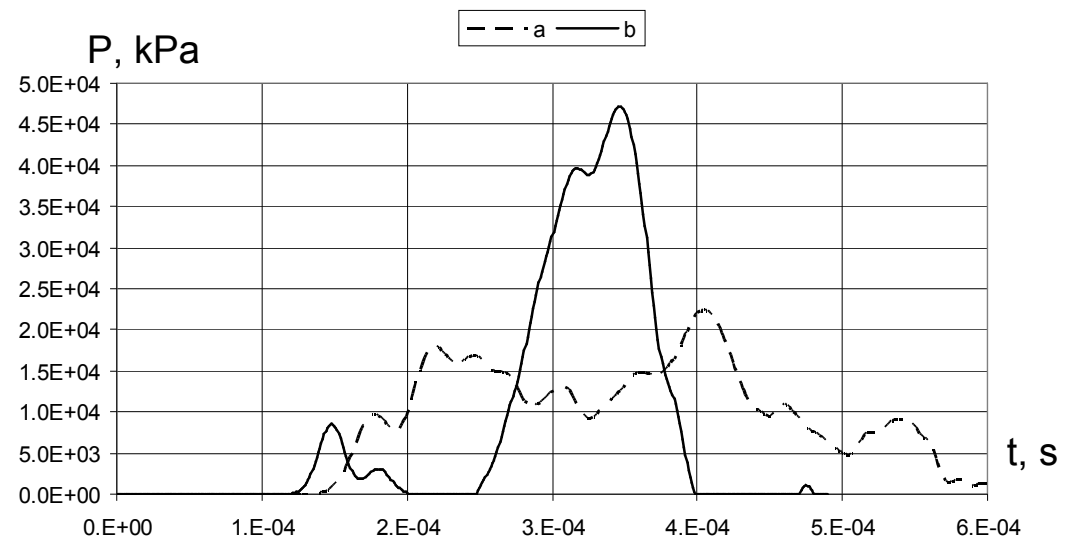

Figure 29. Results of numerical simulation for critical area 2 where "a" is the initial design and " $b$ " is the new design. 
More information about potential application of this simulation technique to EHF processes as well as development of other aspects of EHF technology is described in Golovashchenko (2013).

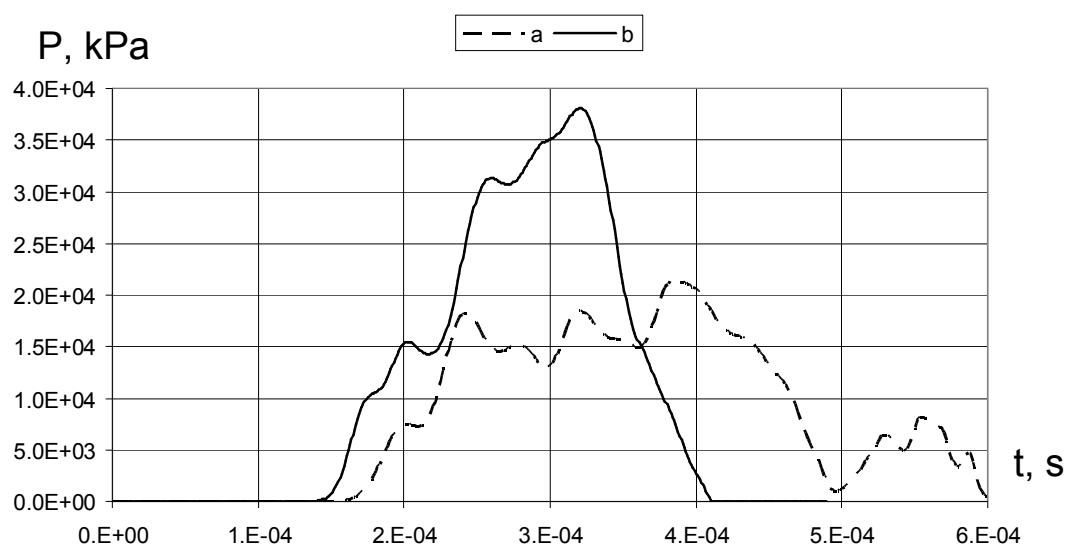

Figure 30. Results of numerical simulation for critical area 3 where "a" is the initial design and "b" is the new design.

Based on comparison of the simulation results of the intuitive EHF chamber design and the optimized chamber configuration, the pressure amplitudes in critical locations were increased factor of $1.5 \ldots 2$ for the same energy of discharge.

\section{Key technological results of the study}

1. EHF provides enhanced formability of sheet metals which can benefit forming of sheet metal forming components from lightweight materials such as aluminum alloys and dual phase steels, especially in the areas of sharp corners which are very difficult to form by traditional stamping operations.

2. EHF has strong potential to lower the requirements for investments into capital equipment: it was demonstrated that to form a license plate with quasistatic hydroforming would require 1200 
tonnes, while the clamping press for the demonstrated EHF process had only 100 tonnes of clamping force.

3. An important capability of the EHF process compared to other pulsed forming processes is the capability to conduct sequential forming steps in a single tool adding necessary amount of water into the chamber after each discharge without opening the chamber.

4. Positioning the electrodes inside the EHF chamber as well as selecting the shape of the chamber should be optimized from the following perspectives: minimizing the volume of the chamber and positioning the electrodes closer to the areas where highest pressure is required usually allows to lower the overall energy consumption and to extend the life of the electrodes. However, positioning the electrodes too close to the surface of the sheet metal blank might lead to the short circuit discharge damaging the surface of the blank.

\section{Conclusions}

Simulation technique for Electro-Hydraulic Forming has been developed using LS-DYNA. The technique incorporates an expanding plasma channel with energy input from an external electrical circuit. Further, the simulation incorporates shock wave propagation with a transition to water motion in an almost incompressible stream, multi-fluid interaction (water and plasma) and fluid interaction with Lagrangian structures (blank and the chamber walls), and, finally, high-velocity deformation of the blank into the die.

The employment of Arbitrary Lagrange-Eulerian (ALE) Multi-Material formulation FE elements for the fluids resolves mesh distortion issues and enables the construction of 
technological process models of arbitrary geometrical complexity. The Lagrangian approach is still useful in those cases where better control over fluid mesh density is required.

Numerical experiments were conducted to determine the ranges of initial plasma density and the initial channel size which do not affect the simulation results. Therefore, within their given ranges, these parameters can be adjusted solely to improve simulation stability.

Two experiments were performed to verify the model. The first experiment was conducted with an axisymmetric cylindrical chamber employing a long discharge channel and where pressure was measured at the cylinder wall using a single pressure sensor. The second experiment was conducted in a conical chamber using the membrane pressure measuring method. Results of both sets of experiments showed acceptable correlation with simulation which proves the models ability to predict both the amplitude and distribution of the pressure waves within the discharge chamber.

Further the technique was used to simulate the practical case of multistage EHF of a complex geometry automotive part. The values of model parameters which provided stable simulation of long duration EHF processes were defined. Analysis of the results shows the complex nature of multistage EHF process: a clearly recognizable wave picture during the initial stage of the channel expansion which transitions to almost incompressible water flow during later stages. Comparison of the results of simulation shows acceptable quantitative correlation with the experiments. 


\section{Acknowledgement}

This material is based upon work supported by the Advanced Manufacturing Office of the United States Department of Energy under Award Number DE-FG36-08GO18128.

\section{Disclaimer}

This report is prepared as an account of work sponsored by an agency of the United States Government. Neither the United States Government nor any agency thereof, nor any of their employees, makes any warrantee, express or implied any legal liability or responsibility for the accuracy, completeness, or usefulness of any information, apparatus, product, or process disclosed, or represents that its use wouldn't infringe any privately owned rights. Reference herein to any specific commercial product, process or service by trade name, trademark, manufacturer, or otherwise does not necessarily constitute or imply its endorsement or recommendation or favoring by the United States Government or any agency thereof. The views and opinions of authors expressed herein do not necessarily state or reflect those of the United States Government or any agency thereof. 


\section{References}

Bäumer A., Jiménez J. A., Cugy P., 2008. Investigation of the strain-hardening behaviour of modern lightweight steels considering the forming temperature and forming rate, Directorate-General for Research and Innovation, European Commission, pp. 78, 90.

Bruno, E.J., 1968. High Velocity Forming of Metals, American Society of Tool and Manufacturing Engineers, Dearborn, MI.

Chachin, V.N., 1978. Electrohydraulic treatment of structural materials. Minsk, Nauka i Texnika, pp.80-87.

Cheah, L., Heywood, J., 2011. Meeting US passenger vehicle fuel economy standards in 2016 and beyond. Energy Policy 39, 454-466.

Cole, R.H., 1948. Underwater Explosions. Princeton, New Jersey, pp.18-176.

Davies, R., Austin, E.R., 1970. Development in High Speed Metal Forming. Industrial Press Inc, New York, USA.

Golovashchenko S.F., 2013. Electrohydraulic Forming of Near-Net Shape Automotive Panels. US Department of Energy. Industrial Technologies Program. DOE Award Number: DE-FG36-08GO18128. Final report. http://www.osti.gov/scitech/servlets/purl/1094831

Golovashchenko S.F., Gillard A.J., and Mamutov A.V., 2013. Formability of Dual Phase Steels in Electrohydraulic Forming. Journal of Materials Processing Technology 213: 1191-1212.

Golovashchenko, S.F., Bessonov, N.M., Ilinich, A.M., 2011. Two-step method of forming complex shapes from sheet metal. Journal of Materials Processing Technology, 875-885.

Golovashchenko, S.F., Gillard, A.J., Mamutov, A.V., Ibrahim, R., 2014. Pulsed electrohydraulic springback

calibration of parts stamped from advanced high strength steel. Journal of Materials Processing Technology 214: $2796-2810$. 
Melander, A., Delic, A., Bjorkblad, A., Juntunen, P., Samek, L., Vadillo, L., 2013. Modelling of electrohydraulic free and die forming of sheet steels. International Journal of Material Forming, 6, Issue 2, 223-231.

Mynors, D.J., Zhang, B., 2002. Applications and capabilities of explosive forming. Journal of Materials Processing Technology 125-126, 1-25.

Naugolnych, K.A., Roy, N.A., 1971, Electric Discharges in Water (Moscow: Nauka) in Russian, 102.

Psyk, V., Risch, D., Kinsey, B.L., Tekkaya, A.E., Kleiner, M., 2011. Electromagnetic forming - A review. Journal of Materials Processing Technology 211,787-829.

Rinehart, J.S. and Pearson, J.,1963. Explosive working of metals. A Pergamon Press Book. The Mamillan Company, New York.

Singh, H., 2003. Fundamentals of hydroforming. Society of Manufacturing Engineers, Dearborn, p.29-35.

Simunovic, S., 1999. Steel Processing Properties and their Effect on Impact Deformation of Lightweight Structures, Quarterly Report 10/19/1999, Oak Ridge National Laboratory, 14, http://thyme.ornl.gov/aisi/reports/aisi1099.pdf

Vagin V.A., Zdor G.N., Mamutov V.S., 1990. Methods of research of high-speed deformation of metals (rus), Nauka I Technika, Minsk.

Vohnout, V.J., Fenton, G., Daehn, G.S., 2010. Pressure heterogeneity in small displacement electrohydraulic forming process. Proceedings of $4^{\text {th }}$ International Conference on High Speed Forming, Columbus, OH, USA, pp.65-74.

Wijayathunga, V.N., Webb, D.C., 2006. Experimental evaluation and finite element simulation of explosive forming of square cup from a brass plate assisted by a lead plug. Journal of Materials Processing Technology, 172, 139145. 


\section{Figure and Table Captions}

Figure 1. Schematic of sheet metal forming with an EHF chamber and die.

Figure 2. Schematic of electrical circuit at high-voltage discharge in a liquid: C - capacitance of the battery; L total inductance of the system; R0 - resistance of the circuit external to the discharge channel; $\mathrm{R}_{\mathrm{v}}-$ resistance of the discharge channel.

Figure 3. Schematic of experimental measurement of energy deposition and pulsed pressure in the discharge chamber: 1 -pulse generator, 2 - cylindrical discharge chamber filled with water, 3 - initiating wire, 4 - Rogowski coil which triggers oscilloscope, 5 - Rogowski coil for the current measurement, 6 - integrating $R C$-circuit, 7 voltage divider, 8 - membrane pressure sensor, 9 - impulse oscilloscope.

Figure 4. Experimentally obtained current $i(t)$ and voltage $u(t)$ vs. time (a) and energy deposition law $N(t)$ (b).

Figure 5. The plain-strain test case mesh.

Figure 6. Pulsed discharge channel: an interface between the plasma channel and water moving through the mesh.

Figure 7. Diameter of discharge channel versus time.

Figure 8. Distribution of the pressure in the cylindrical chamber at different times. Horizontal axis on the charts is the distance from the chamber center $(\mathrm{mm})$, vertical - pressure $(\mathrm{MPa})$.

Figure 9. Experimental tooling: a - discharge chamber connected to the pulse generator and the measuring circuit of discharge current and voltage; $b$ - chamber venting channels.

Figure 10. The die showing multiple free forming windows and channels for air removal during discharge.

Figure 11. IF steel blank formed in the testing chamber using a $13 \mathrm{kV}$ charging voltage $\left(U_{0}\right)$.

Figure 12. Results of simulation of discharge channel expansion between parallel electrodes.

Figure 13. Strain-rate dependent hardening curves for IF steel according to Simunovic (1999).

Figure 14. Example pressure distribution versus time simulation in the conical chamber for the charging voltage of $U_{0}=13 \mathrm{kV}$.

Figure 15. The pressure in the chamber at different points on blank surface. The charging voltage is $U_{0}=13 \mathrm{kV}$.

Figure 16. Evolution of bulge height during the discharge.

Figure 17. The design of the license plate pocket. 
Figure 18. Strain-rate dependent hardening curves for DP500 steel according to Bäumer et al. (2008).

Figure 19. The discharge chamber for the license plate pocket tool.

Figure 20. Experimentally obtained current $i(t)$ and voltage $u(t)$ vs. time (a) and energy deposition law $N(t)$ (b) for the $11 \mathrm{kV}$ discharge in the discharge chamber for the license plate pocket tool.

Figure 21. Discharge channel and blank deformation versus time during first discharge.

Figure 22. Pressure distribution at various times during the first discharge.

Figure 23. Comparison of blank geometry in both simulation and experiment.

Figure 24. Comparison of blank geometry during quasistatic (a) and EHF (b) hydroforming. Cross-section shown is the same marked in Figure 16.

Figure 25. The most critical areas in the die cavity requiring the highest corner filling pressure. Symmetrical areas are marked in pairs as 1,2 , and 3 .

Figure 26. Initial EHF chamber configuration for forming of the license plate area designed prior to the development of the EHF process numerical model.

Figure 27. Modified configuration of the EHF chamber reducing the volume of the chamber and the distances to the critical areas.

Figure 28. Results of numerical simulation for critical area 1 where "a" is the initial chamber design from Figure 23 and "b" is the new chamber design from Figure 24.

Figure 29. Results of numerical simulation for critical area 2 where " $a$ " is the initial design and "b" is the new design.

Figure 30. Results of numerical simulation for critical area 3 where "a" is the initial design and "b" is the new design.

Table 1. Numerical effect from initial channel radius on the maximum pressure at the wall

Table 2. Numerical effect from initial channel density on maximum pressure on chamber wall

Table 3. Results of one discharge at $13 \mathrm{kV}$

Table 4. Comparison the deflection from experiment and simulation 